\title{
The American Association for Thoracic Surgery consensus guidelines for the management of empyema
}

K. Robert Shen, MD, ${ }^{\mathrm{a}}$ Alejandro Bribriesco, MD,${ }^{\mathrm{b}}$ Traves Crabtree, MD, ${ }^{\mathrm{c}}$ Chad Denlinger, MD ${ }^{\mathrm{d}}$ Joshua Eby, MD, ${ }^{\mathrm{e}}$ Patrick Eiken, MD, ${ }_{\mathrm{f}}$ David R. Jones, MD, ${ }^{\mathrm{g}}$ Shaf Keshavjee, MD, MSc,

Fabien Maldonado, MD, ${ }^{i}$ Subroto Paul, MD ${ }^{j}$ and Benjamin Kozower, MD $^{b}$

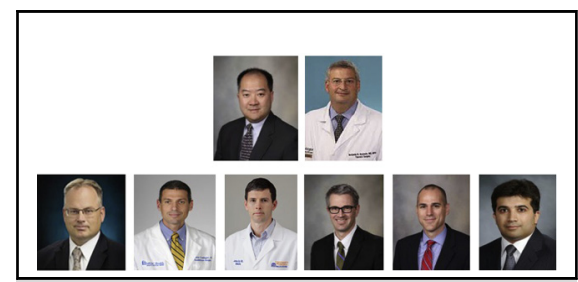

AATS Empyema Guidelines Writing Group: K. Robert Shen, MD, Benjamin Kozower, MD, Traves Crabtree MD, Chad Denlinger, MD, Joshua Eby, MD, Patrick Eiken, MD, Fabien Maldonado, MD, Subroto Paul, MD.

\section{Central Message}

The study objective was to establish The American Association for Thoracic Surgery (AATS) evidence-based guidelines for the management of empyema.

See Editorial Commentary page e147.

\section{TABLE OF CONTENTS}

Objective . . . . . . . . . . . . . . . . . . e130

Methods of Review . . . . . . . . . . . . . . . e130

Introduction . . . . . . . . . . . . . . . . . . e130

Clinical Presentation . . . . . . . . . . . . . . . . . e131

Recommendations . . . . . . . . . . . . . . e131

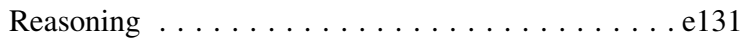

Imaging Studies . . . . . . . . . . . . . . . . . . e132

Recommendations . . . . . . . . . . . . . e132

Reasoning ...................... e132

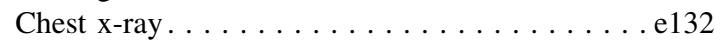

Pleural US . . . . . . . . . . . . . . e132

From the a Department of Surgery, Mayo Clinic College of Medicine, Rochester, Minn; 'bepartment of Surgery, Washington University School of Medicine, Barnes Jewish Hospital, St. Louis, Mo; ' SIU Healthcare, Department of Surgery, Springfield, Ill; ${ }^{\mathrm{d} D e p a r t m e n t}$ of Surgery, Medical University of South Carolina, Charleston, SC; ${ }^{\mathrm{e}}$ Department of Medicine, Infectious Diseases and International Health, University of Virginia, Charlottesville, Va; ${ }^{f}$ Department of Radiology, Mayo Clinic College of Medicine, Rochester, Minn; ${ }^{\mathrm{g}}$ Memorial Sloan Kettering Cancer Center, Thoracic Service, Department of Surgery, New York, NY; ${ }^{\mathrm{h}}$ Toronto General Hospital, Division of Thoracic Surgery, Toronto, Ontario, Canada; ${ }^{\mathrm{i} D e p a r t m e n t ~ o f ~ M e d i c i n e, ~ P u l m o n a r y ~ \& ~ C r i t i c a l ~ C a r e ~ M e d i c i n e, ~ V a n d e r b i l t ~ U n i-~}$
Computed tomography . . . . . . . . . . . e132

Positron emission tomography and magnetic resonance imaging $($ MRI $\ldots \ldots \ldots \ldots \ldots \ldots$. . . . . . . . . . . . . 132 Laboratory and Pleural Fluid Analysis. . . . . . . . . . e132

Recommendations . . . . . . . . . . . . . . e132

General laboratory studies . . . . . . . . . . e133

Thoracentesis: Technique and sample processing. . . e133

Pleural fluid analysis and biomarkers. . . . . . . . e133

Pleural fluid culture. . . . . . . . . . . . . e133

Acute Pleural Empyema: Antibiotic Treatment. . . . . . . . e133

Recommendations . . . . . . . . . . . . . . . . . . . . . . . . . . 133

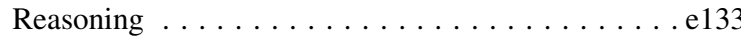

Acute Pleural Empyema: Pleural Drainage. . . . . . . . . . . e134

versity School of Medicine, Nashville, Tenn; and ${ }^{\mathrm{j}}$ Department of Thoracic Surgery, RWJBarnabas Health, Livingston, NJ.

Received for publication Aug 25, 2016; revisions received Dec 24, 2016; accepted for publication Jan 8, 2017; available ahead of print March 6, 2017.

Address for reprints: K. Robert Shen, MD, Division of General Thoracic Surgery, Department of Surgery, Mayo Clinic, 200 First St SW, Rochester, MN 55905

(E-mail: Shen.KRobert@mayo.edu).

J Thorac Cardiovasc Surg 2017;153:e129-46

$0022-5223 / \$ 36.00$

Copyright $\odot 2017$ by The American Association for Thoracic Surgery

http://dx.doi.org/10.1016/j.jtcvs.2017.01.030 


\section{Abbreviations and Acronyms \\ AATS $=$ The American Association for Thoracic Surgery \\ $\mathrm{BPF}=$ bronchopleural fistula \\ $\mathrm{CT}=$ computed tomography \\ $\mathrm{CXR}=$ chest $\mathrm{X}$-ray \\ $\mathrm{IOM}=$ Institute of Medicine \\ LOE $=$ level of evidence \\ MRI = magnetic resonance imaging \\ US $=$ ultrasound \\ VAC $=$ vacuum-assisted closure \\ VATS $=$ video-assisted thoracoscopic surgery}

Thoracentesis . . . . . . . . . . . . . . . . . . . . e e134

Recommendation. . . . . . . . . . . . . . e134

Image-Guided Drain Placement. . . . . . . . . . . . . . . . e134 . . . . . . . . . . . .

Recommendations . . . . . . . . . . . . . . e134

Reasoning. . . . . . . . . . . . . . . . . . . . . . e134

Acute Pleural Empyema: Intrapleural Fibrinolytic Therapy e135

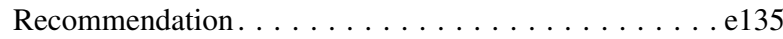

Reasoning ................. e135

Acute Pleural Empyema: Surgical Management . . . . . . . e135

Recommendation. . . . . . . . . . . . . . . e135

Reasoning .................. . e135

Potential Benefits of VATS Over Open Thoracotomy . . . . e136

Potential Harm of VATS Over Open Thoracotomy . . . . . . e136

Summary of Relevant Available Evidence . . . . . . . . . e136

Quality: Retrospective, Cohort (LOE B)/Quantity:

10+ Studies/Consistency: Satisfactory . . . . . . . . . e136

Expert Clinical Opinion. . . . . . . . . . . . . . . . . . . . . . . . . e137

Chronic Empyema . . . . . . . . . . . . . . . . e137

Overview . . . . . . . . . . . . . . e137

Chronic Empyema: Decortication . . . . . . . . . . . . . e137

Recommendations . . . . . . . . . . . . . . . . . . . . . . 137

Reasoning . . . . . . . . . . . . . e137

Potential Benefits of Epidural Anesthesia for Postoperative

Pain Control . . . . . . . . . . . . . . . e138

Potential Harm of Epidural Anesthesia for Postoperative

Pain Control . . . . . . . . . . . . . . e138

Chronic Empyema: Space Filling of Chronic Empyema

Cavities. . . . . . . . . . . . . . . e138

Recommendations . . . . . . . . . . . . . . . e138

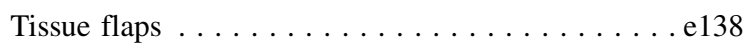

Thoracoplasty . . . . . . . . . . . . . . . e138

Reasoning. . . . . . . . . . . . . . . . e138

Chronic Empyema: Prolonged Treatment Measures. . . . . e139

Open Thoracic Window . . . . . . . . . . . . . . . . . . . . . . . . e139

Recommendation. . . . . . . . . . . . . . . . . . e139

Wound Vacuum-Assisted Closure (VAC) Device . . . . . e139

Recommendation. . . . . . . . . . . . . . . e139

Empyema Tube. . . . . . . . . . . . . . . . . . e139

Recommendation. . . . . . . . . . . . . . . e139

Reasoning. . . . . . . . . . . . . . . . . . . . e139

Postresectional Empyema. . . . . . . . . . . . . . . e140
Postpneumonectomy Empyema . . . . . . . . . . . . . . . . . . . 140

Recommendations . . . . . . . . . . . . . . . e140

Reasoning. . . . . . . . . . . . . . . . . e140

Empyema Associated with BPF . . . . . . . . . . . . e141

Recommendations . . . . . . . . . . . . . . . . e141

Closure devices. . . . . . . . . . . . . . . . . e141

Fistula associated with necrotizing pneumonia . . . e e141

Management of the residual thoracic space. . . . . . e141

Pediatrics. . . . . . . . . . . . . . . . . . . e142

Recommendations . . . . . . . . . . . . . . . . . e142

Conflict of Interest Statement . . . . . . . . . . . . e143

References........................ e143

\section{OBJECTIVE}

The study objective was to establish The American Association for Thoracic Surgery (AATS) evidence-based guidelines for the management of empyema.

\section{METHODS OF REVIEW}

The AATS Guidelines Committee selected management of empyema as a topic suitable for creation of a clinical guideline, and co-chairs (K. Robert Shen, MD, and Benjamin Kozower, MD, thoracic surgeons) were appointed and asked to form an Empyema Management Guidelines Working Group who would create empyema management guidelines for the AATS Guidelines Committee by April 2015. The co-chairs assembled a multidisciplinary group of experts including 5 thoracic surgeons, 1 interventional radiologist, 1 infectious disease specialist, and 1 interventional pulmonologist. Members were tasked with performing comprehensive literature searches and making recommendations based on a review of the literature. Members also graded the quality of the evidence supporting the recommendations and with assessing the risk-benefit profile for each recommendation. The level of evidence (LOE) was graded by the work force panel according to standards published by the Institute of Medicine (IOM; Figure 1). For the development of the guidelines, we consulted the recommendations of IOM 2011 Clinical Practice Guidelines We Can Trust: Standards for Developing Trustworthy Clinical Practice Guidelines (www.iom.edu/cpgstandards) ${ }^{1}$ and followed the IOM recommendations without patient engagement.

Three scheduled teleconferences were used to organize the topics to be covered by the guidelines and review the literature review summaries and proposed recommendations. All meetings had agendas circulated beforehand and minutes circulated afterward. All of the conference calls were recorded by the AATS staff to improve transcription of notes. A 1-day face-to-face conference was then held to formally vote on the final recommendations to present to the Councilors of the AATS and review the final manuscript. All recommendations were subjected to a vote. Acceptance for the final document required greater than $75 \%$ approval of each of the recommendations.

The following recommendations are based on the best available evidence. When high-quality evidence was lacking, we present the best expert opinion based on best practices. An executive summary of these recommendations was prepared for publication in The Journal of Thoracic \& Cardiovascular Surgery. A more extensive version of the guideline was prepared for online publication with additional data and a comprehensive list of references.

\section{INTRODUCTION}

Empyema thoracis, from the Greek, is defined as "pus in the chest." The most common precursor of empyema is 


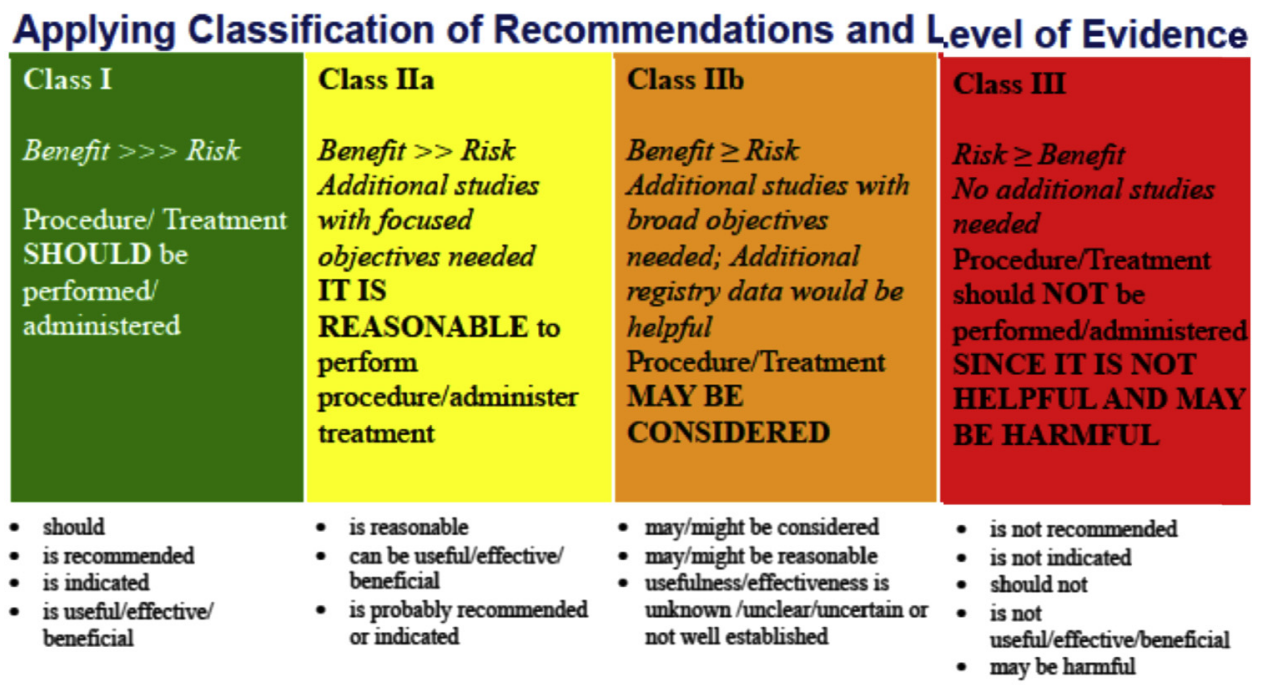

\begin{tabular}{|ll|}
\hline Level A: & $\begin{array}{l}\text { Recommendation based on evidence from multiple randomized trials or meta-analyses } \\
\text { Multiple (3-5) population risk strata evaluated; General consistency of direction and magnitude of effect }\end{array}$ \\
\hline Level B: & $\begin{array}{l}\text { Recommendation based on evidence from a single randomized trial or non-randomized studies } \\
\text { Limited (2-3) population risk strata evaluated }\end{array}$ \\
\hline Level C: & $\begin{array}{l}\text { Recommendation based on expert opinion, case studies, or standard-of-care } \\
\text { Very limited (1-2) population risk strata evaluated }\end{array}$ \\
\hline
\end{tabular}

FIGURE 1. Schema used to guide the grading of available published evidence and the expected effect of the intervention for their impact on patient outcomes.

bacterial pneumonia and subsequent parapneumonic effusion. Other causes of empyema include bronchogenic carcinoma, esophageal rupture, blunt or penetrating chest trauma, mediastinitis with pleural extension, infected congenital cysts of the airway and esophagus, extension from sources below the diaphragm, cervical and thoracic spine infections, as well as postsurgical etiologies. Empyema is an ancient disease that continues to be an important clinical problem. Despite the widespread use of antibiotics and availability of pneumococcal vaccines, empyema remains the most common complication of pneumonia and an important cause of morbidity and mortality worldwide. There are approximately 1 million patients hospitalized in the United States each year with pneumonia. Of those hospitalized, $20 \%$ to $40 \%$ have a parapneumonic effusion, and $5 \%$ to $10 \%$ of these parapneumonic effusions progress to empyema (approximately 32,000 patients per year in the United States). ${ }^{2}$ Approximately $15 \%$ of these patients die, and $30 \%$ require surgical drainage of the pleural space. ${ }^{3,4}$

The incidence of empyema diminished significantly during the first half of the 20th century. ${ }^{5}$ In the preantibiotic era, empyema was a complication of $5 \%$ of cases of pneumonia, but with the development and widespread adoption of antibiotics in the 1940s, the rate of empyema dropped to $2 \%$ of pneumonia cases ${ }^{6}$; however, this trend changed in the 1990s, and the incidence of empyema in the United States has been increasing.

\section{CLINICAL PRESENTATION Recommendations}

1. Class I: The presence of a pleural effusion should be investigated in all patients presenting with signs and symptoms of pneumonia or unexplained sepsis (LOE B).

2. Class I: Failure of a community- or healthcare-associated pneumonia to respond clinically to appropriate antibiotic therapy should prompt investigations to identify the presence of a pleural effusion (LOE B).

Reasoning. Pleural fluid analysis is mandatory because patients with complicated parapneumonic effusions do not differ from those with simple effusions on the basis of clinical presentation. In a large randomized controlled trial, the median duration of symptoms before presentation was 2 weeks. ${ }^{7}$ Anaerobic pleural space infections may present more insidiously with loss of appetite and substantial weight loss and are more likely in patients with poor dental hygiene and at risk for aspiration. $^{8-11}$

Risk factors for progression to complicated parapneumonic effusion and empyema in patients admitted for community-acquired pneumonia include a history of alcohol or intravenous drug use. ${ }^{12}$

Failure of pneumonia to respond clinically to appropriate antibiotic therapy within a few days should suggest progression to pleural space infection. 


\section{IMAGING STUDIES Recommendations}

1. Class I: Pleural ultrasound (US) should be performed routinely in addition to conventional chest $\mathrm{x}$-ray (CXR) in the evaluation of pleural space infection, both for diagnostic purposes and image-guidance for pleural interventions (LOE B).

2. Class IIa: Computed tomography (CT) of the chest should be obtained when pleural space infection is suspected (LOE B).

\section{Reasoning.}

Chest $x$-ray. Conventional CXR is often the most available imaging modality leading to the identification of a pleural space infection. A minimum of $175 \mathrm{~mL}$ of pleural fluid is necessary to result in blunting of the costophrenic angle on a posteroanterior film, although smaller effusions may be identified on a lateral view. ${ }^{13}$ Smaller, loculated effusions may result in lenticular-shaped, pleural-based opacities visible on posteroanterior views but may be difficult to distinguish from underlying parenchymal consolidation. Traditional teaching suggests that lateral decubitus films should be obtained and pleural effusions $>1 \mathrm{~cm}$ thick measured from the lateral chest wall should be sampled. However radiologically complex parapneumonic effusions, however, often are loculated and unlikely to layer dependently and may therefore be missed by conventional CXRs. In a recent study including 61 patients with CT-proven parapneumonic effusions, anteroposterior, posteroanterior, and lateral CXRs all missed approximately $10 \%$ of pleural effusions, in most cases due to the coexistence of lower lobe consolidation. ${ }^{14}$ Although useful as a first step in the investigation of a pleural space infection, CXRs should therefore be combined with additional imaging.

Pleural US. Pleural US has in the past decade become the cornerstone of imaging studies for the evaluation of pleural effusions. It is at least as effective as lateral decubitus CXRs to identify small pleural effusions and better than CXRs at estimating the volume of the effusion, while not being hindered by adjacent consolidations or intrathoracic structures. ${ }^{15}$ The bedside availability of US, which can be performed competently by nonradiologists, makes it an ideal tool to guide safe and effective diagnostic thoracentesis. ${ }^{16-18}$ Pleural US can in addition be performed at the bedside, allowing rapid evaluation in the emergency department or the intensive care unit. ${ }^{19-21}$ Several ultrasonographic patterns have been described in a study including 320 patients, which correlate with pleural fluid characteristics. Complex septated, complex nonseptated, and echogenic pleural effusions typically are exudative, and homogeneously echogenic effusions correspond to hemorrhage or empyema. Transudative effusions are anechoic, but anechoic effusions may be exudative in $27 \%$ of the cases. Pleural thickening also is indicative of exudative pleural effusion. ${ }^{21}$ Two studies suggest that increased septations as assessed by thoracic US may be predictive of clinical outcomes. ${ }^{22,23}$

Computed tomography. Contrast-enhanced CT with tissue phase is a valuable imaging tool in the assessment of pleural-space infections. In addition, it allows a detailed examination of parenchymal abnormalities and may reveal a cause for the pleural space infection, such as bronchogenic carcinoma, endobronchial foreign body, or esophageal rupture. Loculated empyemas, typically lenticular in shape and associated with compression of the adjacent lung parenchyma, generally can be distinguished from pleural based lung abscesses. ${ }^{24,25}$ Empyemas are associated with parietal pleural thickening in $86 \%$ and pleural enhancement in $96 \%$ of patients. ${ }^{26}$ Concurrent thickening and enhancement of both the visceral and parietal pleural can lead to the "split pleura sign," seen in $68 \%$ of empyemas. ${ }^{26}$ High attenuation of the extrapleural adipose tissue in the chest wall suggests empyema and virtually excludes a transudative effusion. ${ }^{26-29}$ The presence of air bubbles within the pleural effusion in the absence of preceding pleural intervention is specific for a pleural space infection and may suggest resistance to chest tube drainage alone. ${ }^{30}$ A pleural fluid thickness cutoff of 2 to $2.5 \mathrm{~cm}$ has been suggested to guide thoracentesis, because smaller effusions on CT are likely to resolve with antibiotics alone. ${ }^{31,32}$

Positron emission tomography and magnetic resonance imaging (MRI). Positron emission tomography does not appear useful in the diagnosis of pleural-space infections, because it does not accurately distinguish inflammatory from malignant pleural effusions. ${ }^{33-35}$ MRI eventually may become an attractive alternative to CT. MRI is useful in distinguishing transudates from exudates and allows assessment of extension into soft tissues, such as in chest wall or spinal involvement. ${ }^{36}$

\section{LABORATORY AND PLEURAL FLUID ANALYSIS Recommendations}

1. Class I: The presence of pus, positive Gram's stain, or culture in the pleural fluid establishes the diagnosis of empyema, which should be treated with tube thoracostomy followed by surgical intervention when appropriate (LOE B).

2. Class I: A pleural $\mathrm{pH}<7.2$ in a patient with suspected pleural space infection predicts a complicated clinical course, and tube thoracostomy should be performed followed by surgical intervention when appropriate (LOE B).

3. Class IIa: A pleural fluid LDH $>1000 \mathrm{IU} / \mathrm{L}$, glucose $<40 \mathrm{mg} / \mathrm{dL}$, or a loculated pleural effusion suggests that the pleural effusion is unlikely to resolve with 
antibiotics alone, and we recommend tube thoracostomy (LOE B).

4. Class I: Obtain pleural fluid culture specimens during aspiration or drainage procedures, not from previously inserted tubes or drains (LOE B). Inoculate freshly drained pleural fluid into aerobic and anaerobic blood culture vials in addition to sterile containers for gram stain and culture (LOE B).

General laboratory studies. Although pleural fluid analysis remains the single most important predictor of clinical outcomes, certain general laboratory data have been associated with an increased likelihood of progression to a pleural space infection in patients admitted for communityacquired pneumonia (see the section "Clinical Presentation") and should be investigated: hypoalbuminemia $(<30 \mathrm{~g} / \mathrm{dL})$, hyponatremia $(<130 \mathrm{mmol} / \mathrm{L})$, and elevated C-reactive protein $(>100 \mathrm{mg} / \mathrm{L}) .{ }^{12}$ Blood cultures are positive in a minority of patients with pleural-space infection. ${ }^{3}$ Thoracentesis: Technique and sample processing. There is in general no possibility to predict based on imaging alone whether a parapneumonic effusion will have a complicated clinical course and therefore diagnostic thoracentesis is indicated in all suspected parapneumonic effusion when the pleural fluid thickness is $>1 \mathrm{~cm}$ on CXR and $>2 \mathrm{~cm}$ on $\mathrm{CT}^{37,38}$ Loculated and large pleural effusions, however, are likely to be associated with a complicated clinical course irrespective of pleural fluid analysis. $^{39,40}$ In addition, several studies have demonstrated that pleural fluid analysis may substantially differ from one locule to another, limiting the value of pleural fluid analysis in this instance..$^{8,41,42}$

Diagnostic thoracentesis should be performed with US guidance to reduce the risk of pneumothorax. ${ }^{16-18} \mathrm{~A}$ frankly purulent appearance obviates the need for pleural $\mathrm{pH}$ analysis. The pleural fluid $\mathrm{pH}$ (see the section "Pleural fluid analysis and biomarkers") should be measured with an arterial blood gas analyzer within 1 hour of sampling. ${ }^{43-45}$ Residual lidocaine, heparin (decrease), or air in the syringe (increase) may affect the $\mathrm{pH}$ results in a clinically meaningful way. ${ }^{43}$

Pleural fluid analysis and biomarkers. In general, purulence of the pleural fluid or a positive Gram's stain or culture from the pleural fluid establishes the diagnosis of empyema and should prompt tube thoracostomy drainage, ${ }^{38,46,47}$ although exceptions may occur. ${ }^{48}$ In the absence of these factors, a large meta-analysis suggests that pleural $\mathrm{pH}<7.2$ is the next most useful predictor of a complicated clinical course in the absence of adequate chest tube drainage. ${ }^{49}$ If pleural $\mathrm{pH}$ is not measured, a pleural fluid glucose value $<40 \mathrm{mg} / \mathrm{dL}$ should prompt chest tube drainage. ${ }^{38,49}$ Likewise, a pleural fluid $\mathrm{LDH}$ value $>1000$ IU/L is also predictive of the need for tube thoracostomy. ${ }^{38,49}$ An additional rare situation is that of pleural space infections caused by urease-splitting organisms such as Proteus species, which may result in a spuriously elevated pleural $\mathrm{pH}^{50}$

Pleural fluid culture. Culture specimens should be obtained in all cases of acute bacterial empyema. Because $44 \%$ of cultures from previously placed catheters or tubing are inaccurate, ${ }^{51}$ it is recommended that culture specimens are acquired during aspiration or drainage procedures. When combined with standard laboratory culture, inoculation of BACTEC culture bottles (Becton, Dickinson, and Company, Franklin Lakes, NJ), by properly trained individuals, improves culture yields. ${ }^{52,53}$ Swabs should not be used for culture. If only a small amount of fluid is available, then fluid should be inoculated only into the standard specimen culture container. Pleural fluid analysis for cell count and chemistries should always accompany pleural fluid cultures.

\section{ACUTE PLEURAL EMPYEMA: ANTIBIOTIC TREATMENT}

\section{Recommendations}

1. Appropriate empiric antibiotic therapy for acute pleural empyema incorporates an understanding of (1) the patient's clinical history, (2) local antimicrobial resistance patterns, (3) institutional antibiotic stewardship, and (4) pharmacologic characteristics of the antibiotics. Recommendations include:

a. Class IIa: For community-acquired empyema: a parenteral second- or third-generation cephalosporin (eg, ceftriaxone) with metronidazole or parenteral aminopenicillin with $\beta$-lactamase inhibitor (eg, ampicillin/sulbactam) (LOE C).

b. Class IIa: For hospital-acquired or postprocedural empyema: include antibiotics active against methicillinresistant Staphylococcus aureus and Pseudomonas aeruginosa (eg, vancomycin, cefepime, and metronidazole or vancomycin and piperacillin/tazobactam [dosed for activity against $P$ aeruginosa]) (LOE C).

c. Class I: Avoid aminoglycosides in the management of empyema (LOE B).

d. Class IIa: There is no role for intrapleural administration of antibiotics (LOE C).

2. Class I: If possible, choose antibiotic therapy based on culture results (LOE C).

a. Class IIa: Consider continuing anaerobic coverage empirically when the anaerobic cultures are negative (LOE C).

3. Class IIb: The duration of antibiotic therapy for acute bacterial empyema is influenced by the organism, adequacy of source control, and clinical response (LOE C).

Reasoning. Choice of empiric antimicrobials should be guided by clinical history, local antimicrobial resistance 
patterns, antimicrobial stewardship policies, and pharmacologic properties of antibiotics. For patients with community-acquired pleural empyema in whom the risk for methicillin-resistant $S$ aureus and highly resistant gram-negative infection is low, a second-generation or a nonpseudomonal, third-generation cephalosporin (eg, ceftriaxone) or an aminopenicillin with $\beta$-lactamase inhibitor (eg, ampicillin/sulbactam) will provide activity against the most commonly identified organisms. ${ }^{54-58}$ Anaerobic organisms should be treated empirically and, whereas ampicillin/sulbactam is active against a range of anaerobes, ceftriaxone requires the addition of an agent such as metronidazole. Clindamycin is a suitable alternative to metronidazole for most upper gastrointestinal and respiratory anaerobic infections. ${ }^{59}$ Even when there is a positive, monomicrobial, aerobic culture to direct therapy, it often is reasonable to continue anaerobic coverage because of the frequency with which anaerobes infect empyemas and because of the inconsistent success at culturing these organisms. ${ }^{60}$ Empiric antibiotics with activity against atypical organisms generally are not necessary. ${ }^{60,61}$ In the setting of hospital-acquired or postsurgical infection, vancomycin, cefepime and flagyl, or vancomycin and piperacillin/tazobactam (dosed adequately for $P$ aeruginosa) will cover the added risk of methicillin-resistant $S$ aureus and Pseudomonas. Vancomycin and meropenem may be indicated if there is a history or suspicion of extended spectrum $\beta$-lactamase-producing organisms. Aminoglycosides are inactivated in empyema fluid and are not recommended. There is no evidence that direct administration of antibiotics into the pleural space increases microbial clearance or outcomes in comparison with systemic antibiotics alone. In many cases of slowly progressing or chronic empyemas, empiric therapy can be held until culture results are available for directed therapy. It is recommended that a infectious diseases consultation is undertaken to assist with diagnosis and therapy for chronic empyema.

Duration of therapy for empyema has not been studied in comparative trials. A range of 2 to 6 weeks of antibacterial therapy for acute empyema is reported in the literature, and this Working Group recommends a minimum of 2 weeks from the time of drainage and defervescence. The final duration should be determined by the sensitivities of the infecting organism, the adequacy of drainage, and the response to therapy on follow-up. If the patient has responded to therapy, there has been source control, the isolated organism is susceptible to orally bioavailable agents, and the patient is tolerating oral intake, then a transition to oral therapy can be made. Chronic empyema should be managed in conjunction with an infectious diseases consultation.

\section{ACUTE PLEURAL EMPYEMA: PLEURAL DRAINAGE \\ Thoracentesis}

Recommendation. Class III no benefit: Thoracentesis without pleural drain placement is not recommended for the treatment of parapenumonic effusion or empyema (LOE C).

Thoracentesis is a useful tool in the management of uncomplicated pleural effusion and a recommended step in the diagnosis of complicated effusion. In the setting of known pleural infection, however, ongoing pleural drainage is regarded as a requirement for adequate treatment and thoracentesis alone, without pleural drain placement, is not recommended.

\section{Image-Guided Drain Placement Recommendations.}

1. Class I: Image-guided pleural drain placement is useful in the treatment of early-stage, minimally septated empyema (LOE B).

2. Class IIa: In septated effusions, placement of small bore catheters are recommended in patients that are not surgical candidates (LOE C).

3. Class I: Routine drain flushing is recommended to prevent occlusion (LOE B).

4. Class I: Tube thoracostomy should be combined with close CT follow-up to confirm adequacy of drainage. Persistence of any undrained fluid should prompt additional drains or more aggressive management (LOE C).

Reasoning. Drainage of infected material from the pleural space is a fundamental part of empyema treatment. Traditionally, tube thoracostomy has been performed with large-bore catheters, but no consensus exists regarding ideal drain size. Initial studies using smaller drains placed with imaging guidance reported success rates around $80 \%$, which were favorable relative to success rates in earlier studies of large-bore drains. ${ }^{62-66} \mathrm{~A}$ recent and widely cited study included 405 patients; it demonstrated equivalent success rates with the use of tubes $\leq 14-\mathrm{F}$ and tubes $>14 \mathrm{~F}^{67}$ Tube size in this study, however, was not randomized; it is likely that patients with more complicated effusions or effusions returning frank pus received larger drains. Based on this evidence, small-bore tubes have become an accepted alterative as first-line therapy in patients amenable to tube thoracostomy alone. ${ }^{68}$

Expert opinion holds that small-bore catheters are ineffective in draining thick pus or extensively septated effusions; however, absent any randomized trials, the role of empyema stage in the success or failure of image-guided drain placement is unclear. Existing data are mixed. In an unblinded trial, the presence of sonographic septations was predictive of more aggressive 
treatment but did not specifically address the success or failure of tube drainage in this population. ${ }^{23}$ In a study of 103 patients, success rates for US-guided small-bore drainage of empyema was greater when the pleural fluid was anechoic sonographically, indicating a lack of septation (92\%), than when there was sonographic evidence of extensive septation $(63 \%) .{ }^{69}$ Another study, however, did not find the imaging appearance of empyema to be predictive of success or failure of tube drainage. ${ }^{70} \mathrm{~A}$ case series has described the successful use of small-bore tunneled catheters in 2 patients with chronic complicated empyema who were not candidates for further surgery. ${ }^{71}$ Further study is needed regarding on the role of empyema stage on the success of tube thoracostomy as a first-line therapy.

The primary causes of drain failure are occlusion and dislodgement. Drain occlusion occurs more commonly with empyema than with uncomplicated pleural effusion or pneumothorax, with reported blockage rates typically from $11 \%$ to $30 \%,{ }^{72}$ with one relatively large study demonstrating a blockage rate of $64 \%$ in their empyema subgroup. ${ }^{73}$ Because of the high rate of drain blockage, drain flushing generally is considered routine. ${ }^{68,72,74}$ Ideal frequency and volume of flushing are not well established, but in one study, flushing with $20 \mathrm{~mL}$ of sterile saline every 6 hours was shown to reduce occlusion rate. ${ }^{75}$ Drain dislodgement also is common. ${ }^{75,76}$ Although drain position usually is assessed by CXR, they can be insensitive in the detection of malpositioned tubes. ${ }^{77}$ In patients treated with tube thoracostomy, CT is superior to CXR in identifying drain dislodgement or undrained pleural fluid. ${ }^{72}$ Any undrained loculations should be pursued aggressively with additional or larger drains. Failure to achieve complete pleural drainage or failure of clinical improvement should prompt more aggressive management, including lytic therapy or surgery.

\section{ACUTE PLEURAL EMPYEMA: INTRAPLEURAL FIBRINOLYTIC THERAPY}

\section{Recommendation}

Class IIa: Intrapleural fibrinolytics should not be used routinely for complicated pleural effusions and early empyemas (LOE A).

Reasoning. Intrapleural fibrinolytics have been used to treat empyema and complicated pleural effusions for the past 65 years. ${ }^{78}$ Because fibrin deposition and the formation of loculations and adhesions characterize the fibrinopurulent phase of empyema, it seems reasonable that fibrinolytic therapy may successfully treat this disease before there is an established pleural rind. This is an extremely important public health and healthcare use issue because the frequency of empyema continues to increase in the United States. $^{79}$

A systematic review of the literature in accordance with the Preferred Reporting Items for Systematic Reviews and
Meta-Analyses identifies 8 prospective, placebo-controlled trials using fibrinolytics in the treatment of empyema and parapneumonic effusions dating back to $1997 .^{80}$ Table 1 illustrates the sample size, chest tube size, and type of fibrinolytic used in the 6 randomized controlled trials performed since $2000 .^{81-85}$ The 2 largest trials are the Multicenter Intrapleural Sepsis Trials 1 and 2 (MIST1 and MIST2). MIST1 showed that streptokinase increased the amount of pleural fluid drainage but was not associated with reduced mortality, frequency of surgery, or length of hospital stay. MIST2 demonstrated that the combination of intrapleural tissue plasminogen activator and DNase had a statistical and clinical improvement in pleural drainage and a reduction in hospital stay. In addition, there was a $75 \%$ reduction in the need for surgical intervention at 3 months.

A thorough meta-analysis on the utility of intrapleural fibrinolytic therapy published in 2012 concluded that fibrinolytic therapy potentially is beneficial in the management of parapneumonic effusions and empyemas in adults but that there is insufficient evidence to support the routine use of this therapy for all patents with parapneumonic effusions/ empyemas. ${ }^{86}$ The authors carefully highlight issues with patient and treatment heterogeneity that confound the results.

The British Thoracic Society published guidelines on the management of pleural diseases in $2010 .^{68}$ They concluded that there was no indication for the routine use of intrapleural fibrinolytics in patients for pleural infection. That recommendation, however, was prepared before the MIST2 trial was published. Ultimately, the difficulty in synthesizing the available information lies in the heterogeneity of patients included in the studies and the various treatments used to treat their pleural space infections. Furthermore, the primary endpoint of most studies was the reduction of pleural fluid seen on CXR after the administration of intrapleural fibrinolytics. To truly create an informed guideline, it would be critical to know long-term outcomes such as pulmonary reserve after treatment and the amount of time before returning to full activity/work. There is a strong perception throughout many of these studies that surgical intervention is to be avoided. Under the care of a dedicated thoracic surgeon, a thoracoscopic or open intervention remains the gold standard for treating complicated pleural effusions/empyemas and those topics are covered separately in this statement.

\section{ACUTE PLEURAL EMPYEMA: SURGICAL MANAGEMENT \\ Recommendation}

Class IIa: Video-assisted thoracoscopic surgery (VATS) should be the first-line approach in all patients with stage II acute empyema (LOE B).

Reasoning. Once the decision has been made to proceed with operative intervention, the choice of open versus thoracoscopic approach must be made with 2 primary goals in mind: (1) complete evacuation of potentially infected fluid 
TABLE 1. Randomized controlled trials of fibrinolytic therapy performed since 2000

\begin{tabular}{|c|c|c|c|c|c|}
\hline Study & Year & Sample size & Chest tube size, $F$ & Intervention & Outcomes \\
\hline Tuncozgur et $\mathrm{al}^{81}$ & 2001 & 49 & $24-36$ & $\begin{array}{l}\text { Urokinase, 100,000 IU } \\
\mathrm{OD} \times 3 \mathrm{~d}\end{array}$ & $\begin{array}{l}\text { Pleural fluid drainage } \\
\text { Length of stay } \\
\text { Rate of surgical intervention }\end{array}$ \\
\hline Diacon et $\mathrm{al}^{82}$ & 2004 & 53 & $24-28$ & $\begin{array}{l}\text { Streptokinase, 250,000 IU } \\
\text { OD } \times 7 \mathrm{~d}\end{array}$ & Rate of surgical intervention \\
\hline Misthos et $\mathrm{al}^{83}$ & 2005 & 127 & $28-32$ & $\begin{array}{l}\text { Streptokinase, 250,000 IU } \\
\text { OD } \times 3 \mathrm{~d}\end{array}$ & $\begin{array}{l}\text { Length of stay } \\
\text { Rate of surgical intervention }\end{array}$ \\
\hline MIST1 & 2005 & 454 & $12(12-20)$ & $\begin{array}{l}\text { Streptokinase, 250,000 IU } \\
\text { OD } \times 3 \mathrm{~d}\end{array}$ & $\begin{array}{l}\text { Mortality } \\
\text { Rate of surgical intervention }\end{array}$ \\
\hline MIST2 & 2011 & 210 & $<15$ & $\begin{array}{l}\text { Alteplase } 10 \mathrm{mg} \text { bid } \times 3 \mathrm{~d} \text { and } \\
\text { DNase } 5 \mathrm{mg} \text { bid } \times 3 \mathrm{~d}\end{array}$ & $\begin{array}{l}\% \text { of hemothorax occupied by effusion } \\
\text { Rate of surgical intervention } \\
\text { Length of stay }\end{array}$ \\
\hline 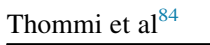 & 2012 & 68 & $14-28$ & Alteplase $25 \mathrm{mg}$ OD $\times 3 \mathrm{~d}$ & Rate of surgical intervention \\
\hline
\end{tabular}

$O D$, Once per day; bid, twice a day.

and/or material and (2) complete re-expansion of the lung. With either approach, the main technical considerations include safe access into the chest, drainage of pleural space, and maneuvers to allow full expansion of lung (ie, release of inferior pulmonary ligament) resulting in obliteration of dead space in the hemithorax. By definition, stage II empyema does not have an organized pleural peel and thus formal decortication is not necessary. However in clinical practice, however, patients rarely present with a "pure" stage II empyema but rather a "mixed stage" with areas of fibrinous organization on the pleural surface.

Since its introduction, the definition of what constitutes a VATS procedure has been debated. It is our opinion that the distinguishing feature of VATS is the absence of rib spreading with avoidance of retractors or instruments that place pressure on the underlying intercostal neurovascular bundle. In our view, the number or size of incisions used for port access is less important than rib distraction.

\section{POTENTIAL BENEFITS OF VATS OVER OPEN THORACOTOMY}

The literature supports multiple benefits of VATS for many clinical applications in the treatment of pulmonary, pleural, esophageal, and mediastinal disease. ${ }^{87}$ Specific benefits that have been demonstrated when comparing VATS treatment of acute empyema versus thoracotomy include improved postoperative pain control, shorter length of stay, less blood loss, less respiratory compromise, and reduction in postoperative complications including 30-day mortality. ${ }^{88}$ Another factor in favor of the VATS approach is its lower cost compared with open thoracotomy. Although not studied specifically in the setting of empyema, VATS has been shown in 3 large retrospective database analyses to afford significant cost savings for both pulmonary wedge resections and lobectomies compared with open thoracotomy. ${ }^{89-91}$

\section{POTENTIAL HARM OF VATS OVER OPEN THORACOTOMY}

In the majority of patients, there is relatively little potential harm with VATS as an initial intervention, given the overall safety profile of diagnostic thoracoscopy coupled with the relative ease of conversion to open thoracotomy if needed. Potential contraindications to VATS include inability to tolerate one-lung ventilation and severe coagulopathy. The potential drawbacks of VATS include increased operative time, increased cost, steeper learning curve, and incomplete therapy, requiring additional procedures. However many of the studies endorsing these caveats, however, were performed before advancements in technology, industry, surgical training/familiarity, and other historical factors, which over time have been ameliorated. ${ }^{92}$

\section{SUMMARY OF RELEVANT AVAILABLE EVIDENCE Quality: Retrospective, Cohort (LOE B)/Quantity: 10+ Studies/Consistency: Satisfactory}

Chambers et al $^{89}$ reviewed 14 studies to specifically address the question of VATS versus open approach to adults with empyema. The majority of studies analyzed were single-institution, retrospective cohort studies with number of patients studied ranging from 48 to 420 and most groups included a mix of stage II and stage III empyema. The outcomes of these studies were consistent in demonstrating that VATS offers superior clinical outcomes in terms of treatment of empyema while also resulting in decreased length of stay, less pain, and less overall morbidity.

As with any situation that lacks Level A randomized controlled data, there are several limitations to these studies that should be considered. First, the stage of empyema treated was varied among studies and often within the same study, making direct comparison of outcomes problematic. Given the variability in empyema stages and 
presentation, there was also a variance in description of VATS drainage versus decortication, which would be the specific treatment for stage II and III empyema, respectively. An argument could be made that a true comparison of VATS versus open thoracotomy for empyema can only be made when each treatment group is matched for demographic and disease stages. In practice, the clinical presentation of empyema is often distinct at time of surgery, which makes the establishment of a firm dichotomy between stages II and III challenging, especially when attempting to accrue large numbers of patients.

Another issue to consider is the inherent selection bias of individual surgeons in retrospective studies to favor the open versus VATS approach. As discussed by the Duke group, surgeons in their study may have been influenced to defer VATS and proceed directly to thoracotomy in patients with previous chest surgery and preoperatively documented empyema. ${ }^{93}$ The concept of "preprocedure probability" of conversion to open thoracotomy will understandably sway surgeons in the decision to consider a VATS attempt, as well as influence the length of thoracoscopic time tolerated before opening. Interestingly in the study Tong and colleagues, ${ }^{93}$ when the population of patients who required conversion to open were compared with successful VATS procedures, there were no significant differences in preoperative factors such as previous cardiac or general thoracic procedures. In addition, surgeons with less VATS experience may be justifiably inclined to forgo VATS or allot less time for thoracoscopic advancement of procedure before converting to open. Shahin and colleagues ${ }^{90}$ demonstrated their own departmental learning curve over 3 years beginning with the introduction of VATS at their institution. Given favorable results with increasing VATS experience, this group considers VATS its first choice of therapy for not just acute/early empyema but also advanced stages of disease, given the value of diagnosis and procedural planning in the event that definitive treatment is not achieved.

\section{EXPERT CLINICAL OPINION}

One of the major decision points during any attempted VATS procedure is when to convert to an open thoracotomy. Uncontrollable bleeding, injury to structures not amenable to thoracoscopic repair, and acute intolerance of singlelung ventilation are universal indications for immediate conversion to thoracotomy. With respect to empyema, 2 additional factors that should prompt consideration for conversion are lack of surgical progression and failure to ultimately achieve the 2 goals of empyema therapy (evacuation and expansion). Published conversion rates widely range from $0 \%$ to $41 \%$, with the largest study from the group at Duke, who reported a rate of $11.4 \%{ }^{89,93}$ With regard to progression, there are no studies to date that define a specific time limit after which surgeons should abort VATS in lieu of thoracotomy. Rather, most authors are subjective in stating that thoracotomy should be performed if VATS is not successful in a "timely fashion," which leaves the threshold for conversion to the individual judgment of each surgeon.

Empyema can be described as having a "triphasic" nature of disease as it progresses through its 3 stages and a step-wise approach to invasive management involving tube thoracostomy, VATS and open thoracotomy logically parallels. After review of the available literature on the management of stage II and mixed (II/III) empyema, however, we recommend that VATS should be the first-line approach (see Figure 2). We anticipate an increasing adoption of VATS as a first-line therapy for all stages of empyema as larger studies are performed, and also as surgeons gain increasing experience and comfort with video-assisted surgical procedures.

\section{CHRONIC EMPYEMA}

\section{Overview}

In the third stage of empyema, the turbid thick fluid of stage II begins to organize and form granulation tissue. The granulation tissue and the underlying inflammation of the infectiousness process leads to formation of a peel compressing the visceral pleural surface. Continuation of this process leads to contraction of the hemithorax with rib space narrowing and a mediastinal shift to the effected side.

The principals of treatment of this chronic space necessitate surgical intervention as pleural drainage procedures are no longer effective at this stage. Effective surgical treatment requires removal of purulent collections and debridement of infected tissue followed by obliteration of the empyema space to prevent recurrence. The choice of the initial approach is dictated based on the condition of the patient, pleural space, and underlying lung parenchyma (Figure 3).

\section{CHRONIC EMPYEMA: DECORTICATION Recommendations}

1. Class IIa: Decortication is reasonable in patients with chronic empyemas who are medically operable to tolerate major thoracic surgery (LOE B).

2. Class IIb: There is no compelling evidence that epidural catheters cannot be used safely in patients with chronic empyema if they are otherwise low risk for epidural abscess (LOE C).

Reasoning. Decortication involves peeling off the granulation tissue and/or fibrous peel overlying the visceral and at times parietal pleura to allow for expansion as well debridement of infected tissue. Frankly necrotic lung parenchyma can be resected if warranted. There are limited data to suggest which cases of parenchymal resection are needed but 


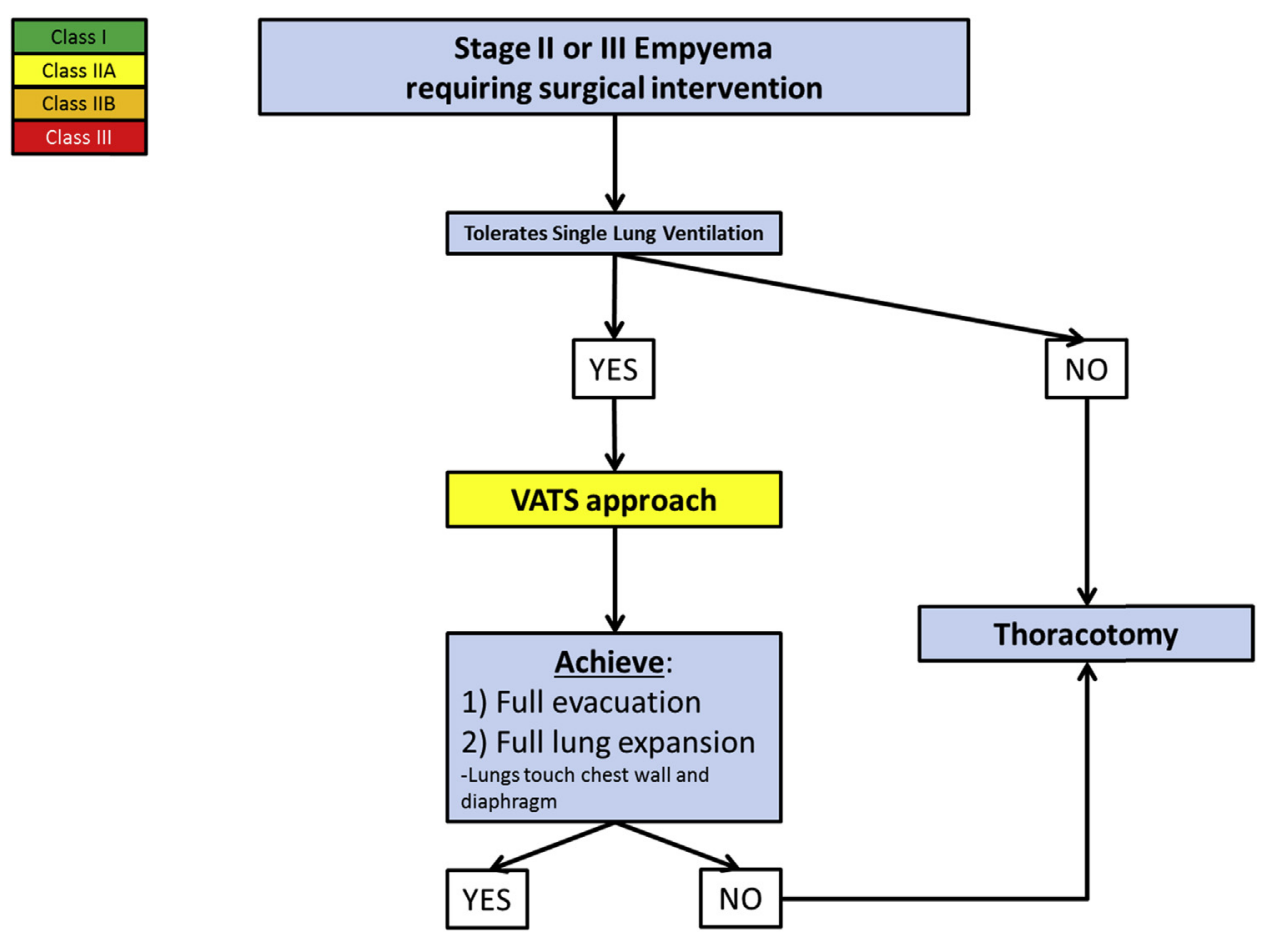

FIGURE 2. Management of acute empyema. VATS, Video-assisted thoracoscopic surgery.

patients with frank abscess serving as sources of sepsis or those with other symptomatology such as hemoptysis should undergo resection. ${ }^{91,94}$

Extensive resections are to be avoided as much as possible because bronchial stumps in infected fields are prone to fistulize. If bronchopleural fistulas (BPFs) are present, they should be closed if possible. However in cases in which lung is resected or fistulas are present, however, muscle flaps may be appropriate for closing the fistula and/or filling in space from incomplete expansion of lung or needed parenchymal resection. Limited studies have examined the functional impact of decortication of chronic empyema on lung function and performance status.

\section{POTENTIAL BENEFITS OF EPIDURAL ANESTHESIA FOR POSTOPERATIVE PAIN CONTROL}

It is well accepted that the use of an epidural catheter for central analgesia improves pain and postoperative function after thoracic surgery. However the use of epidural catheters in patients with empyema, however, generally has been avoided, given the risk of developing an epidural abscess. In general, the 3 main risk factors associated with the development of an epidural abscess of any etiology are compromised immunity, physical disruption of spinal column, and a definitive source of infection. ${ }^{95}$ To date, however, there have been no studies causally linking epidural abscess to placement of epidural catheter in the presence of empyema.

\section{POTENTIAL HARM OF EPIDURAL ANESTHESIA FOR POSTOPERATIVE PAIN CONTROL}

One of the most feared complications of placement of an epidural catheter is the development of an epidural abscess. The rate of this occurrence in all populations range from 1.1 in 100,000 patients to as frequent as 1 in 1930 patients. ${ }^{96}$ Epidural abscess may be a rare event but its consequences are severe, including septic shock and paralysis. Studies specifically examining the incidence or risk of epidural abscess after epidural placement in patients with empyema are difficult to perform, given the overall low incidence of epidural abscess and understandable reluctance to attempt catheter insertion in the setting of pleural space infection.

\section{CHRONIC EMPYEMA: SPACE FILLING OF CHRONIC EMPYEMA CAVITIES \\ Recommendations}

Tissue flaps. Class IIa: Tissue flaps consisting of pedicled muscle flaps or omentum can be useful to fill empyema cavities in which there is space created by incomplete lung expansion or close a BPF (LOE C).

Thoracoplasty. Class IIb: Thoracoplasty with resection of ribs may be considered in select cases to obliterate the infected pleural space where previous measures (muscle flaps, open window) have failed (LOE C).

Reasoning. Incomplete re-expansion of the lung or required resection for necrotic lung parenchyma may 


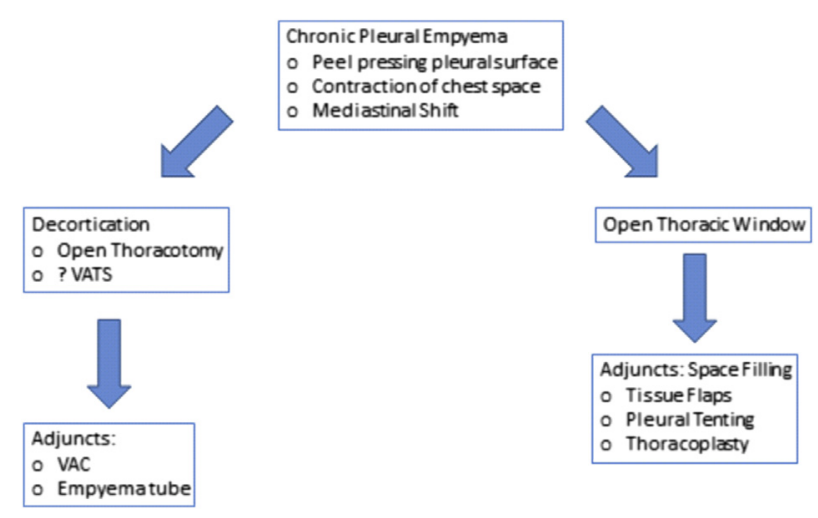

FIGURE 3. Management of chronic empyema.

require the placement of tissue flaps (omentum or muscle) to prevent the reaccumulation of infected pleural fluid. Muscle flaps also have been used to help close BPFs. ${ }^{91,97,98}$

Any extrathoracic muscle can be used and common pedicled flaps include the serratus anterior, latissimus dorsi, and the pectoralis major. Other lower abdominal muscle groups can also be used as complex muscle flaps, but their use should be limited to when chest wall musculature is not available. Omental flaps also can be used. ${ }^{99-101}$ Potential advantages of omental flaps include their inherent wound healing properties. However omental harvest, however, requires abdominal entry, which could lead to another infected cavity. Muscle flaps are best applied in relatively clean wounds devoid of frank purulence. They may be placed at the first operation or reserved after the thoracic cavity has been debridement with fresh granulation tissue through open thoracic window techniques.

Adjunctive measures to decrease the size of the thoracic cavity include pleural tenting and thoracoplasty. ${ }^{91,102}$ Experience with pleural tenting in patients with nonmycobacterium tuberculosis empyemas is limited. More drastic measures for decreasing the pleural cavity space involves resection of the portions of several ribs. Schede thoracoplasty and its more modern versions are morbid and disfiguring. Thoracoplasty is reserved in extreme cases in which previous muscle flaps or open thoracic window techniques have failed. ${ }^{103}$

\section{CHRONIC EMPYEMA: PROLONGED TREATMENT MEASURES \\ Open Thoracic Window}

Recommendation. Class IIa: Open thoracic window with marsupialization of the infected thoracic cavity with resection of several ribs and dressing changes is reasonable to be performed in patients with chronic empyema who are medically unfit to tolerate decortication and tissue flap placement or those patients with chronic empyema with a BPF (LOE C).

\section{Wound Vacuum-Assisted Closure (VAC) Device} Recommendation. Class IIb: Wound VACs may be a reasonable alternative to daily dressing changes to debride chronic pleural cavities that are being treated with an open thoracic window. Caution should be exercised in placing VACs when there is a BPF or visceral pleural rents leading to large air leaks (LOE C).

\section{Empyema Tube}

Recommendation. Class IIb: An empyema tube draining a chronic empyema cavity may be considered in draining chronic infections in which there is a small persistently infected space or small BPF, especially in those patients who are medically unfit to tolerate decortication and tissue flap placement (LOE C).

Reasoning. Patients with chronic empyema often are debilitated or have a BPF, leading to an uncontrolled empyema. These patients often are unable to tolerate an extensive decortication with or without parenchymal resection or tissue flap placement for fistula control. The presence of a BPF may also create a grossly infected space that may need to be controlled before definitive operative repair with decortication and tissue flap placement. ${ }^{91,97,98,104}$

The creation of an open thoracic window allows for this infectious and fistula control either definitely or as part of a stepwise operative plan to definitive surgical treatment of the space. The open thoracic window is created with the creation of marsupialized pleural cavity after the resection of rib space. Patients subsequently undergo dressing changes until the open infected cavity is debrided and the wound begins to form granulation tissue. Recent single-institution studies have evaluated VAC dressing placement as an alternative to dressing changes. By placing a closedsuction sponge device into an infected cavity, VACs drainage may provide superior debridement of infected tissue and promotion granulation tissue formation with less patient discomfort due to less frequent need for VAC sponge changes. ${ }^{105-107}$

Caution, however, should be exercised when placing VACs where a BPF or rents in the visceral pleura of the lung lead to substantial air leaks. In these settings, respiratory compromise may result from suctioning if the significant portions of the patient's lung volume. The placement of nonadherent material to seal the air leaks such as Vaseline Petrolatum Gauze (Unilever US, Inc, Englewood Cliffs, NJ) or similar material may allow for VAC use in these settings. Further investigation of this technology clearly is warranted.

Similar to open thoracic windows, pleural drainage catheters such as chest tubes may be left in chronic empyema cavities to drain infected fluid from pleural cavities with incomplete lung expansion. These tubes may 
be placed at the time of surgical decortication or as a first measure to drainage a chronic empyema in a medically unfit patient. $^{40,71,98,108}$

Large infected pleural cavities may best be drained with an open thoracic window, especially if grossly infected tissue is encountered or a BPF is present. This particularly holds if lung expansion through decortication or tissue placement to cover the BPF is not possible.

\section{POSTRESECTIONAL EMPYEMA}

\section{Postpneumonectomy Empyema}

Recommendations. Class I: Prompt intervention to identify or rule out the presence of a BPF and provide drainage of sepsis is recommended in patients suspected of having postpneumonectomy empyema (LOE C).

Class IIa: An aggressive surgical approach that includes antibiotics, serial debridement, closure of the BPF when present, and obliteration of the residual pleural space using vascularized tissue transposition is a reasonable strategy to manage postpneumonectomy empyema (LOE C).

Reasoning. Infection of the empty pleural space after a pneumonectomy is a serious and potentially fatal complication, with a reported mortality of $28 \%$ to $50 \% .^{109,110}$ The incidence of postpneumonectomy empyema is $5 \%$ after standard pneumonectomy and $10 \%$ after completion pneumonectomy. ${ }^{11-113} \mathrm{BPF}$ is found in more than $80 \%$ of cases of postpneumonectomy empyema.

The first priority in a patient presenting with postpneumonectomy empyema is to identify the presence or absence of a BPF. A fistula should be presumed to be present until an accurate determination can be made by performing flexible bronchoscopy with the patient under local anesthesia in a semiupright position. If the patient presents acutely with clinical features of a BPF, contralateral pneumonitis, and respiratory distress, initial management begins with emergency chest tube drainage of the cavity to control infection and stop contralateral spillage. ${ }^{114}$ The patient preferentially should be positioned in the lateral decubitus position, with the pneumonectomy side down until drainage of the pleural space is obtained. In the patient with empyema without BPF, initial management follows the well-established rules for managing any abscess. These include adequate pleural drainage, appropriate parenteral antibiotics, removal of necrotic and infected tissue, and obliteration of the residual pleural space. ${ }^{115,116}$

There are no randomized or prospective studies that analyzed the best strategy to manage postpneumonectomy empyema, so the recommendations are based on singleinstitution retrospective studies and expert opinion. The most commonly used method of treatment is a modification of that originally described by Clagett and Geraci. ${ }^{117}$ The Clagett procedure as originally described is a 2-stage procedure with open pleural drainage, frequent wet-to-dry dressing changes, and then, when the thorax is clean, secondary chest wall closure with obliteration of the pleural cavity with an antibiotic solution. If a BPF is present, an attempt should be made at the time of debridement of the empyema space to locate and reclose the open bronchial stump. Even if the BPF has developed relatively soon after the pneumonectomy, identification of the bronchial stump can be technically challenging because of the rapid effacement of the hilar structures. Filling the chest cavity with a small amount of saline and having the anesthetist ventilate the bronchial stump can help identify a stream of air bubbles that can be followed to the bronchial stump.

The same principles that should be observed to minimize the chances of developing a postpneumonectomy BPF also should be observed carefully when reclosing the bronchus: (1) Minimize trauma to the end of the bronchus. (2) Preserve blood supply all the way out to the cut end of the bronchus. (3) Carefully approximate the cut edges of the bronchus. (4) Provide adequate tissue reinforcement of the bronchial closure with vascularized tissue. Because failure is caused most often by a persistent or recurrent fistula, the original Clagett technique has been modified to include transposition of a well-vascularized muscle flap to cover and buttress the pneumonectomy stump to prevent further ischemia and necrosis. ${ }^{118}$ In 2006, Zaheer and colleagues ${ }^{119}$ reported on a contemporary series of 84 patients with postpneumonectomy empyema treated using this modified Clagett technique. A total of 84 consecutive patients with postpneumonectomy empyema were treated with open pleural drainage, serial operative debridements, and eventual chest closure after filling the pleural cavity with antibiotic solution. A BPF was present in 55 patients and was closed in all. A vascularized muscle flap was used to reinforce the bronchial stump in $60 \mathrm{pa}-$ tients, 51 with a BPF and 9 without. A total of $81 \%$ of patients had a healed chest wall without evidence of recurrent infection. The BPF remained closed in all patients.

In 2008, Schneiter and colleagues ${ }^{120}$ reported on a series of 75 consecutive patients with postpneumonectomy empyema who were treated successfully in Poland and Switzerland using a similar protocol of serial open surgical debridement of the empyema space, temporary closure of the chest with negative pressure wound therapy, and iodine-soaked dressings. If present, BPFs were closed and reinforced with tissue. In $95 \%$ of patients, the chest could be closed definitively after filling the chest with an antibiotic solution. Postpneumonectomy empyema was treated successfully in $97.3 \%$ of patients, with 10 patients requiring a second treatment cycle. Ninety-day mortality was $4 \%$. 


\section{EMPYEMA ASSOCIATED WITH BPF Recommendations}

1. Class IIa: Closure of BPFs should be attempted with a combination of primary closure and buttressing with a wellvascularized transposed soft-tissue pedicle (LOE C).

2. Class IIb: Transposition of the omentum is preferred over skeletal muscle flaps or mediastinal soft tissue, and this should be attempted after the purulent fluid has been drained completely and the pleural cavity has a surface of granulation tissue (LOE C).

Historically, BPF developed frequently after pulmonary resections with reported rates of $28 \%$ in an era when procedures were being performed primarily for complications related to tuberculosis infections and at a time when less-effective antibiotics were available. More contemporaneously, BPF have still been noted to occur at a frequency of $0.7 \%$ to $7.5 \%$ after pulmonary resections. ${ }^{121-123}$ The risk for a BPF complicating a lobectomy is less than for pneumonectomy. ${ }^{124}$ Reported risk factors for BPF include an index operation for benign disease, right pneumonectomy, completion pneumonectomy, diminished pulmonary reserve, and an extended lymph node dissection. ${ }^{124}$

To date, there have been no prospective studies evaluating different treatment strategies for managing $\mathrm{BPF}$, and our current literature is limited to singleinstitution retrospective case series. An empyema associated with a BPF most often is described after the performance of a pneumonectomy. Less often, BPF have been reported after a lobectomy.

Closure devices. Bronchoscopic interventions to manage BPF have been attempted in some centers with variable results. In a series by Jiang and colleagues ${ }^{125}$ that included a total of 58 had a pneumonecotmy patients, 8 developed a BPF. Attempts to repair the fistula with endoscopic embolization occurred in 5 patients, but this was unsuccessful in each case ${ }^{125}$; however, several case reports and small series have described the use of various devices for the closure of BPF after anatomic lung resections. Amplatzer vascular occlusion devices with or without the addition of bioglue has been used successfully. ${ }^{126-128}$ Other bronchoscopic techniques including cyanoacrylate-based glue, fibrin compounds, gelatin sponges, chemical cautery, endobronchial silicon spigots, and submucosal injection of tissue expanders have been used in small numbers of cases

Fistula associated with necrotizing pneumonia. BPFs associated with thoracic infections occur in the majority of patients after anatomical surgical resections. Less frequently, fistulae occur spontaneously in the setting of a necrotizing pneumonia. In children, fistulae in this setting traditionally has been managed with prolonged chest tube duration. ${ }^{129}$ A more recently described approach to this situation was the rotation of a single segment of the serratus anterior muscle into the chest cavity to close the fistula at the time of a thoracoscopic debridement. In a series of 20 pediatric patients, the median time until resolution of fever was 2 days, and the postoperative length of stay was 9 days. ${ }^{130}$

\section{Management of the residual thoracic space.}

1. Class IIb: Primary chest closure should be attempted with the chest cavity filled with antibiotic solution after granulation tissue has formed in the chest cavity and if the patient is medically fit to undergo another operation (LOE B).

2. Class IIa: The creation of a permanent open thoracostomy window is an acceptable treatment strategy for patients treated for an empyema with a recurrent or persistent BPF who are medically unfit for another operation or for those with recurrent cancer (LOE C).

Three general approaches for management of the thoracic space have been described. The first is a permanent open thoracostomy window. Second, after the infection has been adequately drained, the space can be closed and filled with antibiotic solution. The third option requires obliteration of the thoracic space using soft-tissue muscle or omental flaps with or without the addition of a partial thoracoplasty.

Eloesser ${ }^{131}$ is credited with the creation of a one-way soft-tissue flap valve to allow drainage of pleural fluid while preventing the re-entrance of air. This procedure required the partial resection of 2 to 3 ribs and creating a U- shaped soft-tissue flap that was folded into the chest cavity. Although others have been unable to recapitulate these results, many have adopted a modified version of this operation with an inverted U-shaped muscle flap. The objective of this thoracostomy window is to allow dependent drainage of the pleural space and to provide access to the thoracic cavity for frequent packing.

In a large case series by Puskas and colleagues, ${ }^{121} 31$ patients were treated for empyema associated with BPF after a pneumonectomy. In 16 patients, the thoracic space was obliterated at the time of initial drainage using the omentum of muscle with or without the addition of a partial thoracoplasty. The remaining cavities resolved in 5 patients with adequate drainage and were still open in another 9 patients at the time of last follow-up. One patient was lost to follow-up. The Clagett procedure was performed in 10 patients after the BPF was closed successfully. Six patients successfully cleared the pleural space infection after a single Clagett procedure, and the other 4 patients underwent 2 to 5 procedures in attempt to sterilize the chest cavity. Two patients were able to have their chest permanently closed, one required a permanent thoracostomy window, and one patient died. ${ }^{121}$ 
Permanent drainage of an infected thoracic space also can be achieved by the creation of an open thoracostomy window. This may be a permanent drainage solution for the infected space or may be later closed with a muscle transposition flap or omental pedicle. In a single-institution retrospective series by Regnard and colleagues, ${ }^{122} 46$ patients with postresection empyemas were treated with open thoracostomy windows. Fourteen of these patients also had a concomitant BPF. An open thoracostomy window was the definitive treatment for 10 patients, but in only one case the window closed spontaneously. The remaining patients developed recurrent cancer or were thought to have prohibitive operative risks and did not undergo closure. Thirty-six patients underwent closure with muscle or omental transposition flaps. Three deaths occurred within the first 6 months. Two of these deaths were related to a recurrent empyema and sepsis and one to recurrent cancer. Intrathoracic flap transpositions were successful in $27(75 \%)$ of patients and in the remaining 9 patients $(25 \%)$, the thoracostomy windows were reopened to drain recurrent infections. The presence of a BPF when the empyema was addressed did not impact the success of drainage with an open window thoracostomy or subsequent closure.

In a similar retrospective review of 31 patients with postpneumonectomy empyema, 26 of whom also had a BPF, treated with open thoracostomy windows, closure was attempted in 15 with either muscle transpositions undergoing closure of the thoracostomy window remained free from BPF and recurrent thoracic infection. Factors correlating with the successful closure of a thoracostomy window included the late development of an empyema and immediate creation of a thoracostomy window after identification of the empyema. Trends favoring a successful closure were observed among female patients, left-sided pneumonectomy, index operations for infectious processes, and neoadjuvant chemotherapy but none of these factors were statistically significant. ${ }^{123}$

\section{PEDIATRICS}

\section{Recommendations}

1. Class I: Tube thoracostomy with or without the subsequent instillation of fibrinolytic agents should be attempted as the initial treatment for pediatric patients with an empyema (LOE A).

2. Class IIa: Thoracoscopic debridement and drainage is recommended in pediatric patients not responding adequately to tube thoracostomy and fibrinolytic instillation (LOE B).

3. Class IIa: VATS debridement is preferred rather than open thoracotomy for the surgical management of empyema in the pediatric population (LOE C).
The management of pediatric patients with empyema remains controversial. Some advocate a conservative approach with prolonged chest tube placement and treatment with antibiotics. Others recommend more aggressive surgical intervention, and still others advocate an intermediary approach with the instillation of fibrinolytic agents through chest tubes. A meta-analysis reviewing the existing literature included 54 different studies published between 1981 and 2004 with a total of 3418 patients reviewed. ${ }^{129}$ There were no prospective studies available for review at that time. Patients treated initially with nonoperative therapy $(n=3418)$ that included antibiotics, thoracentesis, or tube thoracostomy had an aggregate mortality of 3.3\% with an overall treatment failure rate of $23.6 \%$. Among those who did not respond to nonoperative treatment, $76.7 \%$ underwent at thoracotomy and $11.2 \%$ had a VATS procedure. The treatment was not specific in the remainder of cases. Patients who were treated primarily with fibrinolytic agents $(n=64)$ had no mortalities and a failure rate of $9.3 \%$. Patients treated with primary surgery $(\mathrm{n}=363)$ had no perioperative deaths and a failure rate of $2.5 \%$. In addition, the length of stay for patients treated with primary surgery (10.8 days) was less than that for patients treated with primary medical therapy (20.0 days). When the surgical approach of thoracotomy versus VATS was compared, patients undergoing VATS procedures had a conversion to thoracotomy rate of $1.1 \%$ and a failure rate of $2.8 \%$ which compared favorably with patients undergoing an initial thoracotomy, which was associated with a $3.3 \%$ failure rate.

More recently a multi-institutional prospective randomized study compared the outcomes of 103 pediatric patients with empyema who were treated with either a thoracostomy tube followed by urokinase or a VATS procedure. ${ }^{132}$ Importantly, this study included only patients $\leq 15$ years old that required thoracostomy tube drainage of a parapneumonic effusion that also had sonographic evidence of septations. The objective of the VATS exploration was to disrupt pleural septations, drain purulent fluid, and irrigate the thoracic cavity but did not include an attempt to completely decorticate the lung. Patients receiving urokinase received twice daily doses of the fibrinolytic agent for 3 days. There were no differences identified between the urokinase and the VATS group with regard to the posttreatment length of hospital stay (10 vs 9 days), total length of hospital stay (14 vs 13 days), or febrile days after treatment (4 vs 6 days) respectively. Secondary interventions were necessary in $15 \%$ and $10 \%$ of the VATS and urokinase groups, respectively.

Three other prospective randomized studies also have compared outcomes of pediatric patients treated with initial VATS debridement to tube thoracostomy and fibrinolytics. There were no mortalities in either of the treatment groups 
in any study. Primary outcomes in each of these 3 studies were hospital length of stay, which were not different between the 2 groups in 2 of the studies (6 vs 6 days and 6.9 vs 8.8 days), ${ }^{133,134}$ but the length of stay was significantly less in the VATS group in one (5.8 vs 13.3 days). ${ }^{135}$

Two studies measured length until fever resolution and there was no difference in one study ( 3.1 vs 3.8 days) $(P=.46),{ }^{133}$ but was different in the other $(2.8$ vs 9.6 days $)(P<.001){ }^{135}$ Sonnappa and colleagues ${ }^{134}$ compared the cost of primary VATS debridment versus tube thoracostomy with fibrinolytics and found that although there was no difference in the hospital length of stay, the overall cost associated with VATS was greater than for patients treated with fibrinolytics $(\$ 11,379$ vs $\$ 9127$ respectively, $P<.001) .{ }^{134}$ Similarly, Kurt and colleagues $^{135}$ found that fibrinolytic treatment was less costly than VATS ( $\$ 7600$ vs $\$ 11,700$ respectively, $P=.02$ ), but St. Peter and colleagues ${ }^{133}$ found no difference in cost between VATS and fibrinolytics $(\$ 19,714$ vs $\$ 21,947$, respectively, $P=312) .{ }^{133,135}$

There were several critical differences in study design. In the study of Kurt and colleagues, ${ }^{135}$ which evaluated a total of 18 patients, the nonoperative group received a chest tube and was later treated with fibrinolytic agents if necessary for incomplete drainage of the pleural fluid. If patients did not have adequate resolution of the effusion, additional catheters were placed for instillation of fibrinolytic agents. In the studies of Sonnappa and colleagues ${ }^{134}$ and St. Peter and colleagues, ${ }^{133}$ which enrolled 60 and 36 patients respectively, fibrinolytic agents were administered by protocol immediately after the chest tube was placed. Another potentially important difference between the 3 studies was the fact that a different fibrinolytic agent was used in each study.

A systematic review of 44 retrospective studies that compared different treatment strategies. The outcomes of patients treated with chest tube alone (16 studies, 611 patients), chest tube with fibrinolytics (10 studies, 83 patients), VATS (22 studies, 449 patients), and thoracotomy (13 studies, 226 patients). ${ }^{136}$ This review identified a shorter length of hospital stay among patients treated with either VATS or thoracotomy compared with those treated nonoperatively. There was also a trend toward a shorter duration of fever among surgically treated patients. The authors concluded that the weight of evidence in these numerous retrospective studies favored early surgical treatment for pediatric patients with empyema.

In the systematic review by Gates and colleagues, ${ }^{136}$ the postoperative length of stay in the VATS and thoracotomy groups were 10.5 and 9.9 days, respectively. Importantly, there were a greater number of studies reviewed reporting the outcomes of patients treated with VATS compared with thoracotomy, and there was a strong trend toward more VATS publications in recent years. Prospective randomized studies have all compared VATS, rather than thoracotomy procedures to chest tube with fibrinolytics. This implies a general shift among practicing surgeons away from open thoracotomy to VATS for the surgical management of empyema.

\section{Conflict of Interest Statement}

Authors have nothing to disclose with regard to commercial support.

\section{References}

1. Institute of Medicine. Clinical practice guidelines we can trust. Available at: http://iom.nationalacademies.org/reports/2011/clinical-practiceguidelines-we-can-trust.aspx. 2011. Accessed December 6, 2015.

2. Light RW. Parapneumonic effusions and empyema. Proc Am Thorac Soc. 2006; 3:75-80.

3. Maskell NA, Batt S, Hedley EL, Davies CW, Gillespie SH, Davies RJ. The bacteriology of pleural infection by genetic and standard methods and its mortality significance. Am J Respir Crit Care Med. 2006;174:817-23.

4. Ahmed RA, Marrie TJ, Huang JQ. Thoracic empyema in patients with community-acquired pneumonia. Am J Med. 2006;119:877-83.

5. Finland M, Barnes MW. Duration of hospitalization for bacteremic infections a Boston City Hospital during 12 selected years between 1935 and 1972. J Infect Dis. 1978;138:837-48.

6. Weese WC, Shindler ER, Smith IM, Rabinovich S. Empyema of the thorax then and now. A study of 122 cases over four decades. Arch Intern Med. 1973;131: 516-20.

7. Maskell NA, Davies CW, Nunn AJ, Hedley EL, Gleeson FV, Miller R, et al. U.K. Controlled trial of intrapleural streptokinase for pleural infection. $N$ Engl J Med. 2005;352:865-74.

8. Bartlett JG, Finegold SM. Anaerobic infections of the lung and pleural space. Am Rev Respir Dis. 1974;110:56-77.

9. Bartlett JG. Anaerobic bacterial infections of the lung and pleural space. Clin Infect Dis. 1993;16(suppl 4):S248-55.

10. Bartlett JG, Gorbach SL, Thadepalli H, Finegold SM. Bacteriology of empyema. Lancet. 1974;1:338-40.

11. Meyer CN, Rosenlund S, Nielsen J, Friis-Møller A. Bacteriological aetiology and antimicrobial treatment of pleural empyema. Scand J Infect Dis. 2011; 43:165-9.

12. Chalmers JD, Singanayagam A, Murray MP, Scally C, Fawzi A, Hill AT. Risk factors for complicated parapneumonic effusion and empyema on presentation to hospital with community-acquired pneumonia. Thorax. 2009;64:592-7.

13. Colins JD, Burwell D, Furmanski S, Lorber P, Steckel RJ. Minimal detectable pleural effusions. A roentgen pathology model. Radiology. 1972;105:51-3.

14. Brixey AG, Luo Y, Skouras V, Awdankiewicz A, Light RW. The efficacy of chest radiographs in detecting parapneumonic effusions. Respirology. 2011; 16:1000-4.

15. Kocijancic I, Vidmar K, Ivanovi-Herceg Z. Chest sonography versus lateral decubitus radiography in the diagnosis of small pleural effusions. J Clin Ultrasound. 2003;31:69-74.

16. Diacon AH, Brutsche MH, Solèr M. Accuracy of pleural puncture sites: a prospective comparison of clinical examination with ultrasound. Chest. 2003;123: 436-41.

17. Duncan DR, Morgenthaler TI, Ryu JH, Daniels CE. Reducing iatrogenic risk in thoracentesis: establishing best practice via experiential training in a zero-risk environment. Chest. 2009;135:1315-20.

18. Jones PW, Moyers JP, Rogers JT, Rodriguez RM, Lee YC, Light RW. Ultrasound-guided thoracentesis: is it a safer method? Chest. 2003;123:418-23.

19. Tayal VS, Nicks BA, Norton HJ. Emergency ultrasound evaluation of symptomatic nontraumatic pleural effusions. Am J Emerg Med. 2006;24:782-6.

20. Vignon P, Chastagner C, Berkane V, Chardac E, Francois B, Normand S, et al Quantitative assessment of pleural effusion in critically ill patients by means of ultrasonography. Crit Care Med. 2005;33:1757-63. 
21. Yang PC, Luh KT, Chang DB, Wu HD, Yu CJ, Kuo SH. Value of sonography in determining the nature of pleural effusion: analysis of 320 cases. AJR Am J Roentgenol. 1992;159:29-33.

22. Chen CH, Chen W, Chen HJ, Yu YH, Lin YC, Tu CY, et al. Transthoracic ultrasonography in predicting the outcome of small-bore catheter drainage in empyemas or complicated parapneumonic effusions. Ultrasound Med Biol. 2009;35:1468-74.

23. Chen KY, Liaw YS, Wang HC, Luh KT, Yang PC. Sonographic septation: a useful prognostic indicator of acute thoracic empyema. J Ultrasound Med. 2000; 19:837-43.

24. Baber CE, Hedlund LW, Oddson TA, Putman CE. Differentiating empyemas and peripheral pulmonary abscesses: the value of computed tomography. Radiology. 1980;135:755-8.

25. Stark DD, Federle MP, Goodman PC, Podrasky AE, Webb WR. Differentiating lung abscess and empyema: radiography and computed tomography. AJR Am J Roentgenol. 1983;141:163-7.

26. Waite RJ, Carbonneau RJ, Balikian JP, Umali CB, Pezzella AT, Nash G. Parietal pleural changes in empyema: appearances at CT. Radiology. 1990; 175:145-50.

27. Aquino SL, Webb WR, Gushiken BJ. Pleural exudates and transudates: diagnosis with contrast-enhanced CT. Radiology. 1994;192:803-8.

28. Takasugi JE, Godwin JD, Teefey SA. The extrapleural fat in empyema: CT appearance. Br J Radiol. 1991;64:580-3.

29. Grijalva CG, Nuorti JP, Zhu Y, Griffin MR. Increasing incidence of empyema complicating childhood community-acquired pneumonia in the United States. Clin Infect Dis. 2010;50:805-13.

30. Smolikov A, Smolyakov R, Riesenberg K, Schlaeffer F, Borer A, Cherniavsky E, et al. Prevalence and clinical significance of pleural microbubbles in computed tomography of thoracic empyema. Clin Radiol. 2006;61: 513-9.

31. Moffett BK, Panchabhai TS, Anaya E, Nakamatsu R, Arnold FW, Peyrani P, et al. Computed tomography measurements of parapneumonic effusion indicative of thoracentesis. Eur Respir J. 2011;38:1406-11.

32. Skouras V, Awdankiewicz A, Light RW. What size parapneumonic effusions should be sampled? Thorax. 2010;65:91.

33. Porcel JM, Hernández P, Martínez-Alonso M, Bielsa S, Salud A. Accuracy of FDG-PET for differentiating benign from malignant pleural effusions: a meta-analysis. Chest. 2015;147:502-12.

34. Toaff JS, Metser U, Gottfried M, Gur O, Deeb ME, Lievshitz G, et al. Differentiation between malignant and benign pleural effusion in patients with extrapleural primary malignancies: assessment with positron emission tomography-computed tomography. Invest Radiol. 2005;40:204-9.

35. Duysinx BC, Larock MP, Nguyen D, Corhay JL, Bury T, Hustinx R, et al. 18FFDG PET imaging in assessing exudative pleural effusions. Nucl Med Commun. 2006;27:971-6.

36. Davis SD, Henschke CI, Yankelevitz DF, Cahill PT, Yi Y. MR imaging of pleural effusions. J Comput Assist Tomogr. 1990;14:192-8.

37. España PP, Capelastegui A, Quintana JM, Soto A, Gorordo I, GarcíaUrbaneja M, et al. A prediction rule to identify allocation of inpatient care in community-acquired pneumonia. Eur Respir J. 2003;21:695-701.

38. Light RW, Girard WM, Jenkinson SG, George RB. Parapneumonic effusions. Am J Med. 1980;69:507-12.

39. Himelman RB, Callen PW. The prognostic value of loculations in parapneumonic pleural effusions. Chest. 1986;90:852-6.

40. Huang HC, Chang HY, Chen CW, Lee CH, Hsiue TR. Predicting factors for outcome of tube thoracostomy in complicated parapneumonic effusion for empyema. Chest. 1999;115:751-6.

41. Light RW, Moller DJ, George RB. Letter: Low pleural fluid pH in parapneumonic effusion. Chest. 1975;68:273-4.

42. Maskell NA, Gleeson FV, Darby M, Davies RJ. Diagnostically significant variations in pleural fluid $\mathrm{pH}$ in loculated parapneumonic effusions. Chest. 2004; 126:2022-4.

43. Cheng DS, Rodriguez RM, Rogers J, Wagster M, Starnes DL, Light RW. Comparison of pleural fluid $\mathrm{pH}$ values obtained using blood gas machine, $\mathrm{pH}$ meter, and $\mathrm{pH}$ indicator strip. Chest. 1998;114:1368-72.

44. Rahman NM, Mishra EK, Davies HE, Davies RJ, Lee YC. Clinically important factors influencing the diagnostic measurement of pleural fluid $\mathrm{pH}$ and glucose. Am J Respir Crit Care Med. 2008;178:483-90.

45. Sarodia BD, Goldstein LS, Laskowski DM, Mehta AC, Arroliga AC. Does pleural fluid $\mathrm{pH}$ change significantly at room temperature during the first hour following thoracentesis? Chest. 2000;117:1043-8.
46. Potts DE, Levin DC, Sahn SA. Pleural fluid pH in parapneumonic effusions. Chest. 1976;70:328-31.

47. Davies CW, Kearney SE, Gleeson FV, Davies RJ. Predictors of outcome and long-term survival in patients with pleural infection. Am J Respir Crit Care Med. 1999;160:1682-7.

48. Berger HA, Morganroth ML. Immediate drainage is not required for all patients with complicated parapneumonic effusions. Chest. 1990;97:731-5.

49. Heffner JE, Brown LK, Barbieri C, DeLeo JM. Pleural fluid chemical analysis in parapneumonic effusions. A meta-analysis. Am J Respir Crit Care Med. 1995;151:1700-8.

50. Pine JR, Hollman JL. Elevated pleural fluid $\mathrm{pH}$ in Proteus mirabilis empyema. Chest. 1983;84:109-11.

51. Everts RJ, Heneghan JP, Adholla PO, Reller LB. Validity of cultures of fluid collected through drainage catheters versus those obtained by direct aspiration. J Clin Microbiol. 2001;39:66-8.

52. Menzies SM, Rahman NM, Wrightson JM, Davies HE, Shorten R, Gillespie SH, et al. Blood culture bottle culture of pleural fluid in pleural infection. Thorax. 2011;66:658-62.

53. Ferrer A, Osset J, Alegre J, Surinach JM, Crespo E, Fernandez de Sevilla T, et al. Prospective clinical and microbiological study of pleural effusions. Eur J Clin Microbiol Infect Dis. 1999;18:237-41.

54. Kaplan SL, Mason EO Jr. Management of infections due to antibiotic-resistant Streptococcus pneumoniae. Clin Microbiol Rev. 1998;11:628-44.

55. Wong CA, Donald F, Macfarlane JT. Streptococcus milleri pulmonary disease: a review and clinical description of 25 patients. Thorax. 1995;50:1093-6.

56. Hammond JM, Potgieter PD, Hanslo D, Scott H, Roditi D. The etiology and antimicrobial susceptibility patterns of microorganisms in acute communityacquired lung abscess. Chest. 1995;108:937-41.

57. Goonetilleke AK, Dev D, Aziz I, Hughes C, Smith MJ, Basran GS. A comparative analysis of pharmacokinetics of ceftriaxone in serum and pleural fluid in humans: a study of once daily administration by intramuscular and intravenous routes. J Antimicrob Chemother. 1996;8:969-76.

58. Wildfeuer A, Ruhle KH, Bolcskei PL, Springsklee M. Concentrations of ampicillin and sulbactam in serum and in various compartments of the respiratory tract of patients. Infection. 1994;22:149-51.

59. Brook I, Wexler HM, Goldstein EJ. Antianaerobic antimicrobials: spectrum and susceptibility testing. Clin Microbiol Rev. 2013;26:526-46.

60. Kroboth FJ, Yu VL, Reddy SC, Yu AC. Clinicoradiographic correlation with the extent of Legionnaire disease. AJR Am J Roentgenol. 1983; 141:263-8.

61. Tan MJ, Tan JS, Hamor RH, File TM Jr, Breiman RF. The radiologic manifestations of Legionnaire's disease. The Ohio Community-Based Pneumonia Incidence Study Group. Chest. 2000;117:398-403.

62. Merriam MA, Cronan JJ, Dorfman GS, Lambiase RE, Haas RA. Radiographically guided percutaneous catheter drainage of pleural fluid collections. AJR Am J Roentgenol. 1988;151:1113-6.

63. Silverman SG, Mueller PR, Saini S, Hahn PF, Simeone JF, Forman BH, et al. Thoracic empyema: management with image-guided catheter drainage. Radiology. 1988;169:5-9.

64. Ulmer JL, Choplin RH, Reed JC. Image-guided catheter drainage of the infected pleural space. J Thorac Imaging. 1991;6:65-73.

65. vanSonnenberg E, et al. CT- and ultrasound-guided catheter drainage of empyemas after chest-tube failure. Radiology. 1984;151:349-53.

66. Westcott JL. Percutaneous catheter drainage of pleural effusion and empyema. AJR Am J Roentgenol. 1985;144:1189-93.

67. Rahman NM, Maskell NA, Davies CW, Hedley EL, Nunn AJ, Gleeson FV, et al. The relationship between chest tube size and clinical outcome in pleural infection. Chest. 2010;137:536-43.

68. Davies HE, Davies RJ, Davies CW; BTS Pleural Disease Guideline Group. Management of pleural infection in adults: British Thoracic Society Pleural Disease Guideline 2010. Thorax. 2010;65(suppl 2):ii41-i53.

69. Shankar S, Gulati M, Kang M, Gupta S, Suri S. Image-guided percutaneous drainage of thoracic empyema: can sonography predict the outcome? Eur Radiol. 2000;10:495-9.

70. Kearney SE, Davies CW, Davies RJ, Gleeson FV. Computed tomography and ultrasound in parapneumonic effusions and empyema. Clin Radiol. 2000;55: 542-7.

71. Davies HE, Rahman NM, Parker RJ, Davies RJ. Use of indwelling pleural catheters for chronic pleural infection. Chest. 2008;133:546-9.

72. Matin TN, Gleeson FV. Interventional radiology of pleural diseases. Respirology. 2011;16:419-29. 
73. Cafarotti S, Dall'Armi V, Cusumano G, Margaritora S, Meacci E, Lococo F, et al. Small-bore wire-guided chest drains: safety, tolerability, and effectiveness in pneumothorax, malignant effusions, and pleural empyema. J Thorac Cardiovasc Surg. 2011;141:683-7.

74. Yu H. Management of pleural effusion, empyema, and lung abscess. Semin Intervent Radiol. 2011;28:75-86.

75. Davies HE, Merchant S, McGown A. A study of the complications of small bore 'Seldinger' intercostal chest drains. Respirology. 2008;13:603-7.

76. Horsley A, Jones L, White J, Henry M. Efficacy and complications of smallbore, wire-guided chest drains. Chest. 2006;130:1857-63.

77. Lim KE, Tai SC, Chan CY, Hsu YY, Hsu WC, Lin BC, et al. Diagnosis of malpositioned chest tubes after emergency tube thoracostomy: is computed tomography more accurate than chest radiograph? Clin Imaging. 2005;29: 401-5.

78. Tillett WS, Sherry S, Read CT. The use of streptokinase-streptodornase in the treatment of chronic empyema; with an interpretive discussion of enzymatic actions in the field of intrathoracic diseases. J Thorac Surg. 1951; 21:325-41.

79. Farjah F, Symons RG, Krishnadasan B, Wood DE, Flum DR. Management of pleural space infections: a population-based analysis. J Thorac Cardiovasc Surg. 2007;133:346-51.

80. Moher D, Liberati A, Tetzlaff J, Altman DG; PRISMA Group. Preferred reporting items for systematic reviews and meta-analyses: the PRISMA statement. J Clin Epidemiol. 2009;62:1006-12.

81. Tuncozgur B, Ustunsoy H, Sivrikoz MC, Dikensoy O, Topal M, Sanli M, et al. Intrapleural urokinase in the management of parapneumonic empyema: a randomised controlled trial. Int J Clin Pract. 2001;55:658-60.

82. Diacon AH, Theron J, Schuurmans MM, Van de Wal BW, Bolliger CT. Intrapleural streptokinase for empyema and complicated parapneumonic effusions. Am J Respir Crit Care Med. 2004;170:49-53.

83. Misthos P, Sepsas E, Konstantinou M, Athanassiadi K, Skottis I, Lioulias A. Early use of intrapleural fibrinolytics in the management of postpneumonic empyema. A prospective study. Eur J Cardio-Thorac Surg. 2005;28:599-603.

84. Thommi G, Shehan JC, Robison KL, Christensen M, Backemeyer LA, McLeay MT. A double blind randomized cross over trial comparing rate of decortication and efficacy of intrapleural instillation of alteplase vs placebo in patients with empyemas and complicated parapneumonic effusions. Respir Med. 2012;106:716-23.

85. Rahman NM, Maskell NA, West A, Teoh R, Arnold A, Mackinlay C, et al. Intrapleural use of tissue plasminogen activator and DNase in pleural infection. $N$ Engl J Med. 2011;365:518-26.

86. Janda S, Swiston J. Intrapleural fibrinolytic therapy for treatment of adult parapneumonic effusions and empyemas: a systematic review and meta-analysis. Chest. 2012;142:401-11.

87. Swanson SJ, Meyers BF, Gunnarsson CL, Moore M, Howington JA, Maddaus MA, et al. Video-assisted thoracoscopic lobectomy is less costly and morbid than open lobectomy: a retrospective multiinstitutional database analysis. Ann Thorac Surg. 2012;93:1027-32.

88. Farjah F, Backhus LM, Varghese TK, Mulligan MS, Cheng AM, AlfonsoCristancho R, et al. Ninety-day costs of video-assisted thoracic surgery versus open lobectomy for lung cancer. Ann Thorac Surg. 2014;98:191-6.

89. Chambers A, Routledge T, Dunning J, Scarci M. Is video-assisted thoracoscopic surgical decortication superior to open surgery in the management of adults with primary empyema? Interact Cardiovasc Thorac Surg. 2010;11: 171-7.

90. Shahin Y, Duffy J, Beggs D, Black E, Majewski A. Surgical management of primary empyema of the pleural cavity: outcome of 81 patients. Interact Cardiovasc Thorac Surg. 2010;10:565-7.

91. Shiraishi Y. Surgical treatment of chronic empyema. Gen Thorac Cardiovasc Surg. 2010;58:311-6.

92. Howington JA, Gunnarsson CL, Maddaus MA, McKenna RJ, Meyers BF, Miller D, et al. In-hospital clinical and economic consequences of pulmonary wedge resections for cancer using video-assisted thoracoscopic techniques vs traditional open resections: a retrospective database analysis. Chest. 2012; 141:429-35

93. Tong BC, Hanna J, Toloza EM, Onaitis MW, D'Amico TA, Harpole DH, et al. Outcomes of video-assisted thoracoscopic decortication. Ann Thorac Surg. 2010;89:220-5.

94. Rathinam S, Waller DA. Pleurectomy decortication in the treatment of the "trapped lung" in benign and malignant pleural effusions. Thorac Surg Clin. 2013;23:51-61. vi.
95. Reihsaus E, Waldbaur H, Seeling W. Spinal epidural abscess: a meta-analysis of 915 patients. Neurosurg Rev. 2000;23:175-204; discussion 205.

96. Grewal S, Hocking G, Wildsmith JAW. Epidural abscesses. Br J Anaesth. 2006; 96:292-302.

97. Miller JI Jr. The history of surgery of empyema, thoracoplasty, Eloesser flap, and muscle flap transposition. Chest Surg Clin N Am. 2000;10:45-53. viii.

98. Akgül AG, Örki A, Örki T, Yüksel M, Arman B. Approach to empyema necessitatis. World J Surg. 2011;35:981-4.

99. Okomise H, Takahashi Y, Inui K, Yagi K, Mizuno H, Aoki M, et al. Omentoplasty for postpneumonectomy bronchopleural fistulas. Eur J Cardiothorac Surg. 1994;8:122-4.

100. Shirakusa T, Ueda H, Takata S, Yoneda S, Inutsuka K, Hirota N, et al. Use of pedicled omental flap in treatment of empyema. Ann Thorac Surg. 1990;50: 420-4.

101. Iverson LI, Young JN, Ecker RR, Ennix CL Jr, Lau G, Stallone R, et al. Closure of bronchopleural fistulas by an omental pedicle flap. Am J Surg. 1986;152: 40-2.

102. Botianu PV, Botianu AM. Thoracomyoplasty in the treatment of empyema: current indications, basic principles, and results. Pulm Med. 2012;2012:418514.

103. Pomerantz BJ, Cleveland JC, Pomerantz M. The Schede and modern thoracoplasty. Op Tech Thorac Cardiovasc Surg. 2000;5:128-34.

104. Schweigert M, Solymosi N, Dubecz A, Fernández MJ, Stadlhuber RJ, Ofner D et al. Surgery for parapneumonic pleural empyema-What influence does the rising prevalence of multimorbidity and advanced age has on the current outcome? Surgeon. 2016;14:69-75.

105. Ahn HY, Cho JS, Kim YD, Hoseok I. Intrathoracic muscular transposition in chronic tuberculous empyema. Thorac Cardiovasc Surg. 2013;61:167-71.

106. Varker KA, Ng T. Management of empyema cavity with the vacuum-assisted closure device. Ann Thorac Surg. 2006;81:723-5.

107. Saadi A, Perentes JY, Gonzalez M, Tempia AC, Wang Y, Demartines N, et al Vacuum-assisted closure device: a useful tool in the management of severe intrathoracic infections. Ann Thorac Surg. 2011;91:1582-9.

108. Ali SM, Siddiqui AA, McLaughlin JS. Open drainage of massive tuberculous empyema with progressive reexpansion of the lung: an old concept revisited. Ann Thorac Surg. 1996;62:218-23; discussion 23-4.

109. Higgins GA, Beebe GW. Bronchogenic carcinoma. Factors in survival. Arch Surg. 1967;94:539-49.

110. Patel RL, Townsend ER, Fountain SW. Elective pneumonectomy: factors associated with morbidity and operative mortality. Ann Thorac Surg. 1992;54:84-8.

111. Eerola S, Virkkula L, Varstela E. Treatment of postpneumonectomy empyema and associated bronchopleural fistula. Experience of 100 consecutive postpneumonectomy patients. Scand J Thorac Cardiovasc Surg. 1988;22:235-9.

112. Grégoire J, Deslauriers J, Guojin L, Rouleau J. Indications, risks, and results of completion pneumonectomy. J Thorac Cardiovasc Surg. 1993;105:918-24.

113. Massard G, Lyons G, Wihlm JM, Fernoux P, Dumont P, Kessler R, et al. Early and long-term results after completion pneumonectomy. Ann Thorac Surg. 1995;59:196-200

114. Barker WL, Faber LP, Ostermiller WE Jr, Langston HT. Management of persistent bronchopleural fistulas. J Thorac Cardiovasc Surg. 1971;62:393-401.

115. Deschamps C, Pairolero PC, Allen MS, Trastek VF. Management of postpneumonectomy empyema and bronchopleural fistula. Chest Surg Clin N Am. 1996; 6:519-27.

116. Wain JC. Management of late postpneumonectomy empyema and bronchopleural fistula. Chest Surg Clin N Am. 1996;6:529-41.

117. Clagett OT, Geraci JE. A procedure for the management of postpneumonectomy empyema. J Thorac Cardiovasc Surg. 1963;45:141-5.

118. Pairolero PC, Arnold PG, Trastek VF, Meland NB, Kay PP. Postpneumonectomy empyema. The role of intrathoracic muscle transposition. J Thorac Cardiovasc Surg. 1990;99:958-66; discussion 966-8.

119. Zaheer S, Allen MS, Cassivi SD. Postpneumonectomy empyema: results after the Clagett procedure. Ann Thorac Surg. 2006;82:279-86.

120. Schneiter D, Grodzki T, Lardinois D, Kestenholz PB, Wojcik J, Kubisa B, et al Accelerated treatment of postpneumonectomy empyema: a binational longterm study. Thorac Cardiovasc Surg. 2008;136:179-85.

121. Puskas JD, Mathisen DJ, Grillo HC, Wain JC, Wright CD, Moncure AC. Treatment strategies for bronchopleural fistula. J Thorac Cardiovasc Surg. 1995;109: 989-95.

122. Regnard JF, Alifano M, Puyo P, Fares E, Magdeleinat P, Levasseur P. Open window thoracostomy followed by intrathoracic flap transposition in the treatment of empyema complicating pulmonary resection. J Thorac Cardiovasc Surg. 2000; 120:270-5. 
123. Massera F, Robustellini M, Pona CD, Rossi G, Rizzi A, Rocco G. Predictors of successful closure of open window thoracostomy for postpneumonectomy empyema. Ann Thorac Surg. 2006;82:288-92.

124. Deschamps C, Bernard A, Nichols FC III, Allen MS, Miller DL, Trastek VF, et al. Empyema and bronchopleural fistula after pneumonectomy: factors affecting incidence. Ann Thorac Surg. 2001;72:243-8.

125. Jiang F, Huang J, You Q, Yuan F, Yin R, Xu L. Surgical treatment for bronchopleural fistula with omentum covering after pulmonary resection for non-small cell lung cancer. Thoracic Cancer. 2013;4:249-53.

126. Bille A, Subarwhal T, Tom R. Vascular occlusion device closure of bronchial stump fistulae: a straightforward approach to manage bronchial stump breakdown. Gen Thorac Cardiovasc Surg. 2012;60:847-50.

127. Gulkarov I, Paul S, Altorki NK, Lee PC. Use of Amplatzer device for endobronchial closure of bronchopleural fistulas. Interact J Cardiovasc Surg. 2009;9: 901-2.

128. Kramer MR, Peled N, Shitrit D, Atar E, Saute M, Shlomi D, et al. Use of Amplatzer device for endobronchial closure of bronchopleural fistulas. Chest. 2008;133:1481-4.

129. Avansino JR, Goldman B, Sawin RS, Flum DR. Primary operative versus nonoperative therapy for pediatric empyema: a meta-analysis. Pediatrics. 2005;115:1652-9.
130. Jester I, Nijran A, Singh M, Parikh DH. Surgical management of bronchopleural fistula in pediatric empyema and necrotizing pneumonia: efficacy of the serratus anterior muscle digitation flap. J Pediatr Surg. 2012;47:1358-62.

131. Eloesser L. Of an operation for tuberculous empyema. Surg Gynecol Obstet. 1969;60:1096-7.

132. Marhuenda C, Barceló C, Fuentes I, Guillén G, Cano I, López M, et al. Urokinase versus VATS for treatment of empyema: a randomized multicenter clinical trial. Pediatrics. 2014;134:1301-7.

133. St Peter SD, Tsao K, Spilde TL, Keckler SJ, Harrison C, Jackson MA, et al. Thoracoscopic decortication vs tube thoracostomy with fibrinolysis for empyema in children: a prospective, randomized trial. J Pediatr Surg. 2009;44: 106-11.

134. Sonnappa S, Cohen G, Owens CM, van Doorn C, Cairns J, Stanojevic S, et al. Comparison of urokinase and video-assisted thoracoscopic surgery for treatment of childhood empyema. Am J Respir Crit Car Med. 2006;174:221-7.

135. Kurt BA, Winterhalter KM, Connors RH, Betz BW, Winters JW. Therapy of parapneumonic effusions in children: video-assisted thoracoscopic surgery vs. conventional thoracostomy drainage. Pediatrics. 2006;118:547-53.

136. Gates RL, Caniano DA, Hayes JR, Arca MJ. Does VATS provide optimal treatment of empyema in children? A systematic review. J Pediatr Surg. 2004;39: 381-6. 